\title{
Promise and challenges for direct small molecule AMPK activators
}

\author{
Benoit Viollet, Séverine Olivier, Marc Foretz, Benoît Viollet
}

\section{To cite this version:}

Benoit Viollet, Séverine Olivier, Marc Foretz, Benoît Viollet. Promise and challenges for direct small molecule AMPK activators. Biochemical Pharmacology, Elsevier, 2018, <10.1016/j.bcp.2018.01.049>. $<$ inserm-01724341>

\section{HAL Id: inserm-01724341 http://www.hal.inserm.fr/inserm-01724341}

Submitted on 6 Mar 2018

HAL is a multi-disciplinary open access archive for the deposit and dissemination of scientific research documents, whether they are published or not. The documents may come from teaching and research institutions in France or abroad, or from public or private research centers.
L'archive ouverte pluridisciplinaire HAL, est destinée au dépôt et à la diffusion de documents scientifiques de niveau recherche, publiés ou non, émanant des établissements d'enseignement et de recherche français ou étrangers, des laboratoires publics ou privés. 


\title{
Promise and challenges for direct small molecule AMPK activators
}

Séverine Olivier ${ }^{1,2,3}$, Marc Foretz ${ }^{1,2,3}$ and Benoit Viollet ${ }^{1,2,3, *}$

${ }^{1}$ INSERM, U1016, Institut Cochin, Paris, France.

${ }^{2}$ CNRS, UMR8104, Paris, France .

${ }^{3}$ Université Paris Descartes, Sorbonne Paris Cité, France.

*Corresponding author: Benoit Viollet, INSERM U1016, Institut Cochin, Dpt Endocrinology, Metabolism and Diabetes, 24 rue du Faubourg Saint-Jacques 75014 Paris, France.

Email: benoit.viollet@ inserm.fr; Tel +33 1444124 01; Fax +33 144412421.

\begin{abstract}
AMP-activated protein kinase (AMPK) is an evolutionary conserved and ubiquitously expressed serine/threonine kinase playing a central role in the coordination of energy homeostasis. Based on the beneficial outcomes of its activation on metabolism, AMPK has emerged as an attractive target for the treatment of metabolic diseases. Identification of novel downstream targets of AMPK beyond the regulation of energy metabolism has renewed considerable attention in exploiting AMPK signaling for novel therapeutic targeting strategies including treatment of cancer and inflammatory diseases. The complexity of AMPK system with tissue- and species-specific expression of multiple isoform combination regulated by various inputs, post-traductional modifications and subcellular localizations presents unique challenges for drug discovery. Here, we review the most recent advances in the understanding of the mechanism(s) of action of direct small molecule AMPK activators and the potential therapeutic opportunities.
\end{abstract}

Key words: AMPK; energy metabolism, small molecule activators; therapeutics; drug discovery 


\section{1- Introduction}

AMP-activated protein kinase (AMPK) is mainly known as a highly conserved and ubiquitously expressed energy sensor that is highly sensitive to changes in cellular energy levels (by sensing increases in AMP:ATP and ADP:ATP ratios) and makes appropriate adjustment to balance the consumption of ATP with its synthesis [1]. In this context, the overall effect of AMPK activation is to increase the rate of catabolic (ATP-generating) processes and decrease the rate of anabolic (ATP-consuming) processes in an attempt to restore cellular energy homeostasis. This is accomplished by the phosphorylation of downstream targets involved in the regulation of numerous metabolic pathways as well as long-term adaptive changes through transcriptional regulation. In addition to its role in maintaining intracellular energy homeostasis, AMPK also coordinates metabolism at the whole-body level [2]. Therefore, AMPK represents a point of conversion of regulatory signals monitoring systemic and cellular energy status, making AMPK signaling an obvious target for the treatment of several metabolic disorders [1,3]. The discovery that muscle contraction activates AMPK in skeletal muscle leading to increased glucose uptake and evidence supporting that skeletal muscle AMPK signaling network is not compromised in type 2 diabetic individuals reinforced the interest for targeting AMPK via physical exercise or pharmacological interventions [3, 4]. Moreover, a growing number of downstream targets that are phosphorylated when AMPK is activated independently of the canonical AMP and ADP inputs have been recently identified, expanding AMPK function beyond its critical role in the regulation of energy homeostasis [5-7]. It was recently demonstrated that AMPK is able to sense glucose availability independently of changes in adenine nucleotides by a mechanism involving the formation of complexes with axin on the surface of the lysosome [8]. Given recent reports highlighting the critical regulatory role played by AMPK in autophagy, antiinflammatory response and cell growth $[9,10]$, it is not surprising to see the heightened interest in the development of AMPK-targeted therapeutics for the potential to offer significant human health benefits.

In this review, we explore the promise and potential challenges of exploiting the versatility of AMPK signaling for novel therapeutic targeting strategies. We provide here an update on recently developed direct AMPK activators, notably focusing on their mechanisms of action and therapeutic opportunities. A detailed description of the role of AMPK in the regulation of whole body and cellular functions is out of scope of the current review and the reader is invited to consult other recent reviews dealing with this specific topic $[5,9,11,12]$. 


\section{2- Structure and regulation of AMPK}

AMPK is a heterotrimeric protein kinase comprised of an alpha $(\alpha)$ catalytic subunit in combination with scaffolding beta $(\beta)$ and regulatory gamma $(\gamma)$ subunits (Figure 1). These subunits are encoded by seven genes (PRKAA1, PRKAA2, PRKAB1, PRKAB2, PRKAG1, PRKAG2, PRKAG3), enabling the formation of a diverse collection of $\alpha \beta \gamma$ heterotrimer combinations. The seven isoforms $(\alpha 1, \alpha 2, \beta 1, \beta 2, \gamma 1, \gamma 2$ and $\gamma 3)$ can theoretically combine to form up to 12 possible heterotrimers with eventually different regulation (expression, turnover, subcellular localization), regulatory properties (sensitivity to various inputs), and functions (specific substrate phosphorylation, different outputs) for unique impact on cellular homeostasis. In addition, reported PRKAG2 transcript variants differentially expressed in adult tissues (with a transcript predominantly expressed in the heart) may also add to the diversity in the composition of AMPK heterotrimers [13, 14].

\section{2-1- Structural features and role of the catalytic a subunits}

The $\alpha$ catalytic subunits contain the conventional serine/threonine kinase domain $(\alpha-\mathrm{KD})$ at the $\mathrm{N}$-terminus while the $\mathrm{C}$-terminus is required for binding the $\beta$ and $\gamma$ subunits (Figure 1 ). Phosphorylation of the conserved threonine residue (Thr172) within the activation loop of the $\alpha-K D$ is required for full activation of AMPK. Two principal upstream kinases have been identified, the tumour suppressor LKB1 [15-17] and the Ca2+/calmodulin-activated kinase 2 (CaMKK2) [18-20]. LKB1 is constitutively active but can be further modulated by posttranslational modifications $[2,21]$. Moreover, LKB1 appears to be a major regulator of AMPKa2, at least in skeletal and cardiac muscle [22, 23]. Activation by CaMKK2 is mediated by increases in cytosolic $\mathrm{Ca}^{2+}$ concentrations, thus providing an alternate pathway to activate AMPK independent of changes in adenine nucleotide concentration. In addition, TGF- $\beta$ activated kinase 1 (TAK1) was proposed as an alternative upstream kinase [24] but only few studies further investigated its physiological relevance [25, 26]. The identity of phosphatase regulating AMPK phosphorylation is largely unknown and may depend on the cell type $[27,28]$. The $\alpha-\mathrm{KD}$ is immediately followed by an auto-inhibitory domain ( $\alpha$-AID) that maintains the $\alpha-\mathrm{KD}$ in an inactive conformation in the absence of AMP $[29,30]$. The $\alpha-$ AID is connected to the globular C-terminal domain ( $\alpha$-CTD) by a flexible regulatory segment ( $\alpha$-linker) playing a key role in allosteric activation of AMPK by AMP [31]. In the presence of AMP, interactions between the $\alpha$-linker with the $\gamma$ subunit restricts its flexibility 
and results in tighter association of the catalytic and nucleotide binding modules, which physically protects Thr172 from dephosphorylation. Moreover, the binding of the $\alpha$-linker to the $\gamma$ subunit shifts the $\alpha$-AID away from the $\alpha$-KD, thus releasing its negative effects on the $\alpha-\mathrm{KD}$. Within the $\alpha$-CTD, a flexible serine/threonine-rich loop termed as the ST loop (only conserved in vertebrates) appears to play a regulatory role in the inhibition of AMPK by other kinases. Phosphorylation of the ST loop reduces the activity of AMPK by decreasing the net phosphorylation of Thr172. Phosphorylation of AMPK $\alpha 1$ at Ser485 and AMPK $\alpha 2$ at Ser491 by PKA [32, 33], Akt [34, 35] and S6K [36] antagonizes AMPK activation. Phosphorylation at other sites within the ST-loop by GSK3 [37], PKC [38] and PKD1 [39] has been also involved in the reduction of AMPK activity. In addition to phosphorylation, AMPK activity is also modulated via post-translational ubiquitination and degradation by ubiquitin ligases specifically targeting the $\alpha 1$-isoform [40] or the $\alpha 2$-isoform [41]. The $\alpha$-CTD terminates with a nuclear export signal [42]. The $\alpha 2$-isoform is found more enriched in the nucleus than the $\alpha 1$-isoform [43]. This may allow the fine-tuning of gene transcription in responses to AMPK activation.

\section{2-2- Structural features and role of the regulatory $\beta$ subunits}

The $\beta$ regulatory subunits contain a myristoylation site at the $\mathrm{N}$-terminus that serves to localize AMPK to membranes allowing translocalization to mitochondria and targeting to developing phagophore [44-47]. In addition, myristoylation also enhances the effect of AMP on the phosphorylation by upstream kinases, suggesting possible preferential activation of AMPK at membrane sites. At the C-terminus, a subunit interaction domain ( $\beta$-SID) acts as a scaffold to link the $\alpha$-CTD to the N-terminus of the $\gamma$ subunit (Figure 1). The $\beta$-subunits also contains a central glycogen binding domain ( $\beta$-GBD) which modulates AMPK activity and causes AMPK to bind to glycogen particles and co-localization with specific targets [48-50]. The GBD of the $\beta 2$-isoform appears to have a higher affinity for glycogen than that of $\beta 1$ [51]. Autophosphorylation at Thr148 that is centrally located in the carbohydrate-binding pocket of the $\beta$-GBD was described to prevent AMPK binding to glycogen, suggesting that the binding affinity of AMPK to glycogen is regulated in response to glycogen content and AMPK activation [52]. However, this mechanism has been challenged in the context of AMPK activation in response to skeletal muscle contraction [53] and the regulation of AMPK via glycogen is likely to occur by an indirect mechanism [54]. 


\section{2-3- Structural features and role of the regulatory $\gamma$ subunits}

The $\gamma$ subunits contain a conserved core of four tandem repeats known as cystathionine $\beta$ synthase (CBS) domain forming four potential nucleotide binding sites (Figure 1). Only three of the CBS repeats are known to bind AMP, ADP or ATP interchangeably, enabling AMPK to sense fluctuations in cellular energy state. While AMP and ADP act as activators of AMPK, binding of ATP antagonizes this effect. Thus, AMP:ATP and ADP:ATP ratios are the intracellular modulators of AMPK activity [55]. Whereas CBS2 is unoccupied because it is not competent to bind any of the adenine nucleotides, CBS 4 retains AMP with high affinity and is described as a "non-exchangeable" site [56]. CBS1 and 3 are the regulatory sites for AMPK activation. Activation of AMPK is mediated through complementary mechanisms mainly based on the flexibility of the $\alpha$-linker that connects the catalytic and nucleotidebinding modules. In the active AMP or ADP bound conformation, phosphorylated AMPK $\alpha$ Thr172 lies in a narrow cleft between the two modules and is protected from dephosphorylation by phosphatases [57, 58]. However, only binding of AMP but not ADP can drive allosteric activation of the enzyme [57]. These two nucleotides have also been shown to promote phosphorylation of AMPK by upstream kinases although the effect of CaMKK2 is controversial $[55,59]$. One possible explanation for why AMP binding promotes phosphorylation by LKB1 came from recent studies showing interaction between AMP bound AMPK and the axin/LKB1 complex at the lysosomal surface $[60,61]$.

\section{3- Diversity of the AMPK heterotrimers}

The complexity of AMPK system with multiple isoform combination presents unique challenges for drug discovery because each AMPK heterotrimer can be viewed as a potential and specific drug target. In addition, there has been only limited knowledge on the AMPK heterotrimeric complexes tissue-specific distribution and specific roles. The question of whether the different isoform combinations have distinct functions remains only partially answered. However, insights in human AMPK molecular diversity and specificity are beginning to emerge and will help to better define therapeutic modalities. In human skeletal muscle, although all seven subunit isoforms of AMPK are expressed at mRNA level, a limited number of distinct combinations of AMPK heterotrimeric complexes have been detected [62]. Only 3 of the 12 possible AMPK heterotrimeric complexes are present to a significant extent $(\alpha 2 / \beta 2 / \gamma 1>>\alpha 2 / \beta 2 / \gamma 3 \geq \alpha 1 / \beta 2 / \gamma 1)$, with a high degree of consistency between species (Figure 2) $[62,63]$. However, although present at one-fifth of all heterotrimers, $\alpha 2 / \beta 2 / \gamma 3$ is the primary complex to be activated in response to high-intensity exercise protocols, indicating 
differential regulation and distinct responsibilities of heterotrimers in the control of cellular response to energy stress [64]. The activation of AMPK in the skeletal muscle has been shown to play a role in the regulation of the glucose uptake by enhancing, similarly to insulin, the translocalization of GLUT4 to the surface membrane [65]. Like Akt which is involved in the signaling of insulin, AMPK is able to phosphorylate the Rab GTPase-activating proteins Tre-2/USP6, BUB2, cdc16 domain family, member 1 (TBC1D1) and TBC1D4 [66]. Once phosphorylated, these downstream targets are inhibited, which leads to the translocalization of GLUT4 to the membrane and then enables the entry of glucose in muscle cells. Interestingly, there is a differential phosphorylation of these targets according to the nature of AMPK heterotrimeric complex activated in response to physical activity. In exercised human skeletal muscle, activity of AMPK $\alpha 2 \beta 2 \gamma 3$ heterotrimer has been correlated with the phosphorylation of TBC1D1 at Ser237 and Thr596, whereas activity of AMPK $\alpha 2 \beta 2 \gamma 1$ heterotrimer correlated to the phosphorylation of TBC1D4 at Ser341 and Ser704 [66]. Similar TBC1D1 phosphorylation signature was reported in exercised skeletal muscle from type 2 diabetic subjects indicating the competence of insulin resistant skeletal muscle for AMPK activation [4]. It is noteworthy that the nature of the different AMPK heterotrimeric complexes also varies between organs (Figure 2), raising the possibility to target AMPK pharmacologically in a tissue-specific manner. In human hepatocytes, AMPK $\alpha 1 \beta 2 \gamma 1$ was identified as the predominant complex $[67,68]$. In contrast, in rodent hepatocytes, the expression of AMPK isoforms was clearly different leading to multiple possible combination of heterotrimers containing either $\alpha 1$ or $\alpha 2$ and $\beta 1, \gamma 1$ and $\gamma 2$ (Figure 1) [67, 68]. This observation of interspecies divergence with respect to the tissue specificity of AMPK heterotrimers is of particular interest for drug discovery purposes as it questions the translation of preclinical data to clinical studies.

\section{4- AMPK as a druggable target}

AMPK signaling has attracted considerable attention within the past decades, owing to the capacity of pharmacological compounds (e.g., 5-aminoimidazole-4-carboxamide riboside" by " 5-aminoimidazole-4-carboxamide-1- $\beta$-D-ribofuranoside [AICAR] and metformin) or natural compounds (e.g., resveratrol) to activate AMPK indirectly via altered cellular energy charge or accumulation of AMP analogs inside cells [1]. However, the development and use of indirect AMPK activators acting via inhibition of mitochondrial complex $\mathrm{I}$ is not recommended due to the potential systemic toxicity and life-threatening lactate acidosis risk, as recently reported for the indirect AMPK activator R118 [69, 70]. In addition, since some of 
the effects of indirect activators could be mediated through off-target effects independently of AMPK activation [71, 72], intense interest has been focused on the development of more specific AMPK activators by using relevant screening systems for identifying compounds that interact directly to activate the AMPK heterotrimeric complex [73, 74]. In 2006, highthroughput screen (HTS) efforts drove the discovery of the first non-nucleotide direct small molecule AMPK activator, A-592017, optimized to generate the more potent compound A769662 [75] (Figure 3), demonstrating that AMPK activation with non-nucleotide ligands is possible. This important breakthrough in AMPK research leads to the development of more specific and potent small molecule AMPK activators and an increasing collection of compounds with diverse chemical structures is now available from the patent and published literature [76-79] (Figure 3). Recent crystallographic studies of AMPK have provided molecular insights into the mechanism and site of action for most of these compounds [8083]. The interface between the GBD and the small lobe of the $\alpha-\mathrm{KD}$ forms a discrete pocket that has been recently identified as a new allosteric binding site, referred to as the allosteric drug and metabolite (ADaM) site [82]. The ADaM site is depicted as an "orphan" allosteric site since no endogenous AMPK ligand has been identified yet. This site appears to be necessary to promote AMPK $\alpha$-Thr172 phosphorylation induced by agents that increase cellular AMP/ADP [84] and thus, represents an attractive site for the pharmacological modulation of AMPK activity. Indeed, it is also accessible to various synthetic activators derived from HTS, including A-769662 and 991 [81, 82] (Figure 3), and the natural product salicylate [81]. Reports of alternative binding sites include the $\gamma$ subunit with compounds identified after screening an AMP mimetic library [80, 85] (Figure 3).

\section{5- Small molecule AMPK activators}

Here, we only illuminated some representative compounds confirmed to directly influence AMPK activity (Figure 3). These small molecules directly bind to specific sites on the AMPK heterotrimeric complex. This binding induces conformational changes leading to AMPK activation through multiple modalities such as allosteric modulation, increase in AMPK $\alpha$ Thr172, protection against Thr172 dephosphorylation or a combination of these mechanisms.

\section{5-1- Direct AMPK activation through binding to the ADaM site}

\section{- $\beta 1$-selective compounds:}


The first synthetic compound in this class is the thienopyridone derivative A-769662 (Figure 3) [75]. A-769662 stimulated partially purified rat liver AMPK or recombinant AMPK $\alpha 1 \beta 1 \gamma 1$ heterotrimer with similar potency $\left(\mathrm{EC}_{50}=0.8\right.$ and $0.7 \mu \mathrm{M}$, respectively) [75]. A769662 activates AMPK both allosterically and by inhibiting AMPK $\alpha$ subunit dephosphorylation at Thr172 [86, 87]. However, its ability to activate AMPK complexes containing AMP-insensitive AMPK- $\gamma 1 \mathrm{R} 298 \mathrm{G}$ or AMPK- $\gamma 2 \mathrm{R} 531 \mathrm{Q}$ mutants indicates binding to a different site than AMP on the AMPK heterotrimeric complex $[87,88]$. In addition, A769662 does not change cellular AMP:ATP and ADP:ATP ratios in intact cells [71, 72]. Important insights of how A-769662 regulates AMPK activity came from crystal structure of AMPK $\alpha 1 \beta 1 \gamma 1$ and $\alpha 2 \beta 1 \gamma 1$ complexes bound to A-769662 [81, 82]. These studies revealed that A-769662 binds to ADaM site to mediate $\beta-G B D / \alpha-K D$ interaction, and stabilize the $\alpha-$ KD in an active conformation. Interestingly, A-769662 exhibits selectively towards AMPK complexes containing the $\beta 1$ - rather than the $\beta 2$-isoform [89] and requires phosphorylation of $\beta 1-S e r-108$ for full activation of AMPK heterotrimers [87]. These observations opened up the possibility of developing small molecule activators with AMPK heterotrimer specificity. In addition, as the first direct AMPK activator available to the scientific community, A-769662 gained much interest to investigate the effect of pharmacological AMPK activation in the absence of changes in cellular energy balance. Of note, few reports indicate that A-769662 can interfere with various biological pathways unrelated to AMPK through multiple off-target effects; thereby, calling into question the use of A-769662 as a specific AMPK activator [63, 71, 90, 91]. Hence, pharmacological studies should be combined with genetic studies examining the role of AMPK in mediating the observed pharmacological outcomes. Since then, numerous studies reporting the therapeutic effets of A-769662 in various preclinical mouse models have provided meaningful advances regarding the potential use of small molecule AMPK activators in therapeutics (a select of few is provided below). AMPK activators may be beneficial for the treatment of a variety of diseases including liver, kidney, cardiovascular and inflammatory diseases as well as diabetes and cancer. The most relevant studies indicating the utility of AMPK activators for the treatment of a number of pathologies are listed in Table 1.

Given clear isoform selectivity for $\beta 1$-containing AMPK complexes and poor expression of $\beta 1$-isoform in skeletal muscle, it is not surprising that A-769662 is unable to stimulate glucose uptake in mouse skeletal muscle [89, 92]. Thus, administration of A-769662 in rodents should offer beneficial metabolic effects that are be expected from a specific AMPK 
activation via $\beta 1$-containing complexes such as in the liver with induction of a switch from glucose to fatty acid utilization and protection against hepatic triglyceride accumulation [93, 94]. Indeed, acute treatment of rats with A-769662 at a dose of $30 \mathrm{mg} / \mathrm{kg}$ i.p. significantly reduces respiratory exchange ratio (RER) after a high carbohydrate bolus consistent with a switch from carbohydrate to fat utilization [75]. These effects were lost in AMPK $\beta 1 \mathrm{KO}$ mice [95]. In addition, chronic treatment of $o b / o b$ mice with $30 \mathrm{mg} / \mathrm{kg}$ b.i.d. A-769662 for 5 days showed a dramatic decrease in liver triglyceride content [75]. The inhibition of hepatic lipid accumulation in response to A-769662 treatment was lost in liver-specific AMPK KO mice fed a high fat diet, demonstrating an AMPK-dependent mechanism [96].

Beside these effects on hepatic lipid metabolism, A-769662-induced AMPK activation specifically in the small intestine through intraduodenal infusion (A-769662 at $3 \mathrm{mg} / \mathrm{kg}$ ) in rat resulted in the reduction of hepatic glucose production in a non-autonomous manner (interorgan crosstalk), mimicking the effects of intraduodenal metformin infusion on the control of glucose plasma level [97]. It was hypothesized that activation of duodenal AMPK contributes in a duodenal glucagon-like peptide-1 (GLP-1) receptor/protein kinase A (PKA) signaling and a neuronal-mediated gut-brain-liver pathway to control hepatic glucose production. These findings highlight the potential development of specific gut-targeted treatments to improve the glycemic control of in individuals with diabetes and obesity.

AMPK has a recognized role in promoting an anti-inflammatory response, reinforcing the interest in AMPK activation for treating inflammatory diseases [98-100]. Because AMPK activity in macrophage is predominately dependent on the $\beta 1$-isoform (Figure 2) [101], the effect of A-769662 was tested in mouse models of inflammatory arthritis. Activation of AMPK by A-769662 at $60 \mathrm{mg} / \mathrm{kg}$, b.i.d. reduced inflammatory cell infiltration and joint damage as well as IL-6 secretion, showing the potential for targeted activation of AMPK in IL-6 dependent inflammatory arthritis [102].

Support for the potential of A-769662 as an effective treatment to protect the heart against ischemia-reperfusion injury in mice has also been reported [103]. A-769662-induced AMPK activation promoted cardioprotection through phosphorylation and inactivation of eukaryotic elongation factor 2 (eEF2) and also phosphorylation and activation of endothelial nitric oxide synthase (eNOS), which plays several protective effects following ischemia. These effects are abrogated in mouse hearts with genetically inactivated AMPK, indicating that A-769662 cardioprotective action is AMPK-dependent [103]. A-769662 also contributes to the cardioprotection via the overstimulation of glucose uptake and glycolysis, subsequently 
decreasing ROS and cardiomyocyte death [104]. These data support the possibility that pharmacological activation of AMPK might be a potential therapeutic strategy to reduce ischemic injury.

Discovery of indole- and indazole-acid-based AMPK synthetic activators led to the development of compounds MT 68-73 (also called Debio 0930) [105], PF-06409577 [106] and PF-249 [107, 108] (Figure 3). These compounds allosterically activate AMPK and protect AMPK- $\alpha$ Thr172 against dephosphorylation [105-107]. As for A-769662, all these compounds activate AMPK through binding at the ADaM site and display high selectively for complexes containing the AMPK- $\beta 1$ isoform compared to the AMPK- $\beta 2$ isoform $[84,105$ 107].

MT 63-78 was able to exert robust growth-inhibitory effects in prostate cancer cells in vitro as well as suppress tumor growth in vivo [105]. Treatment with MT 63-78 (30 mg/kg, i.p.) daily for 14 days of xenograft models promoted AMPK activation in xenograft tumors and significant reduced tumor volume. Prolonged treatment for 21 days with higher dose of MT 63-78 (60 mg/kg, i.p.) resulted in a more robust inhibition of xenograft growth. MT 63-78mediated AMPK activation was associated with inhibition of de novo phospholipid production and a marked decrease in the generation of neutral lipids, suggesting AMPK as a therapeutic target especially for lipogenesis-driven prostate cancers. In addition, it was reported that low doses of MT 63-78 in combination treatment with androgen receptor antagonists/androgen synthesis inhibitors resulted in increased therapeutic response [105].

PF-06409577 and PF-249 showed efficacy in a rat model of diabetic nephropathy, suggesting the potential utility of AMPK activators for the treatment of renal diseases [107] (Table 1). Of note, PF-06409577 was used in a phase I clinical trial for the treatment of diabetic nephropathy but the trial was terminated prematurely for business reasons [109]. Chronic treatment of the ZSF1 rat model of diabetic nephropathy with $100 \mathrm{mg} / \mathrm{kg}$ PF-06409577 or 30 $\mathrm{mg} / \mathrm{kg}$ PF-249 significantly decreased proteinuria in a dose dependent manner following 68 days of dosing, resulting in improvement of kidney function. Beneficial glomerular AMPK activation was associated with reduction of enhanced mechanistic target of rapamycin (mTOR) signaling, an established pathological factor leading to podocyte hypertrophy and compromised filtration barrier [107].

- pan-AMPK compounds:

A series of cyclic benzimidazole derivatives have been identified as relevant AMPK 
activators. In this class, the first compound to be described is the synthetic compound 991 (also known as Ex229) (Figure 3). It was found to bind the ADaM site but it is 5- to 10-fold more potent than A-769662 [82]. It allosterically activates AMPK complexes and enhances protection of the activation loop against dephosphorylation. AMPK complexes containing the $\beta 1$-isoform bind 991 about 10 times stronger than $\beta 2$-isoform. This may explain the weaker activation displayed towards $\beta 2$-containing complexes [82, 110]. However, 991 dosedependently increased AMPK activity of both $\beta 1$ - and $\beta 2$-containing complexes in rat skeletal muscle and stimulated glucose uptake in myotubes by an AMPK-dependent mechanism [92]. As a potent AMPK activator, 991 also strongly inhibited hepatic lipogenesis and stimulated fatty acid oxidation in primary mouse hepatocytes [96].

Two related benzimidazole derivatives PF-739 and MK-8722, were recently discovered as potent pan-AMPK activator (Figure 3) $[108,111]$. They bind to the ADaM site and activate both $\beta 1$ - and $\beta 2$-containing complexes. The clinical relevance for the use of these nonselective pan-AMPK activators in a therapeutic strategy for type 2 diabetes was tested in diabetic mice and non human primates. Acute administration of PF-739 and MK-8722 resulted in activation of AMPK in skeletal muscle associated with glucose lowering effect and increased muscle glucose disposal but without impact on hepatic glucose production. Consistently, the blood glucose-lowering effect of PF-739 was attenuated in the absence of AMPK $\alpha 1$ and $\alpha 2$ in skeletal muscle, whereas it was not affected by the absence of AMPK $\alpha 1$ and $\alpha 2$ in the liver. In addition, chronic pharmacological pan-AMPK activation resulted in sustainable improvements in glucose homeostasis, including the amelioration of insulin resistance and hyperglycemia $[108,111]$. These studies established the powerful therapeutic benefit of AMPK activation in skeletal muscle as a potential type 2 diabetes therapy (Table $1)$.

\section{5-2- Direct AMPK activation through binding to the $\gamma$-subunit}

A synthetic compound C2 (5-(5-hydroxy-isoxazol-3-yl)-furan-2-phosphonic acid) has been identified after screening an AMP mimetic library as a potent allosteric activator of AMPK (Figure 3) [112]. C2 activates AMPK with an $\mathrm{EC}_{50}$ in the low nanomolar range, which is 1000-fold lower than AMP. As AMP, it protects against AMPK $\alpha$-Thr172 dephosphorylation. However, it does not modulate other AMP-regulated enzymes such as glycogen phosphorylase, phosphofructokinase or fructose-1,6-bisphosphatase [80]. This compound showed high potency for activation of AMPK in cells when delivered as a pro-drug, C13, a 
phosphonate diester converted by cellular esterases into $\mathrm{C} 2$. It has been reported that $\mathrm{C} 13$ potently inhibited hepatic lipogenesis and stimulated fatty acid oxidation in primary mouse hepatocytes [80,96] and reduced lipogenesis in mice [112].

Crystal structures of $\mathrm{C} 2$ bound to AMPK revealed two C2-binding sites in the AMPK $\gamma$ subunit distinct from nucleotide-binding sites [85]. The two $\mathrm{C} 2$ molecules bind at the interface of CBS 1, 3, and 4, with the phosphate groups of both $\mathrm{C} 2$ molecules overlapping the phosphate binding sites of AMP in sites 1 and 4. These findings demonstrate that it is possible to develop compounds binding outside the ADaM site and open exciting possibility for developing isoform-selective $\gamma$-binding AMPK activators. C2 activates complexes containing the $\gamma 1$ - and $\gamma 2$-isoforms but not the $\gamma 3$-isoform, suggesting different structural features between the $\gamma$ isoforms that can be exploited in future rational drug design.

Interestingly, C2, like AMP, worked synergistically with A-769662 to activate dephosphorylated AMPK [85]. Unexpectedly, C2 is selective for AMPK complexes containing the $\alpha 1$-isoform rather than $\alpha 2$-isoform [80]. Mutagenesis studies demonstrated the critical role of the regulatory $\alpha$-RIM2 segment in the $\alpha 1$-selectivity of $\mathrm{C} 2$. This was confirmed by swapping the $\alpha$-RIM2 from AMPK- $\alpha 1$ to the $\alpha 2$ isoform which was sufficient to confer full allosteric activation and protection against AMPK $\alpha$-Thr172 dephosphorylation [80].

\section{5-3- Direct AMPK activation through binding to unknown site}

AMPK activity is modulated by interaction between the $\alpha$-AID and $\alpha$-KD. In an effort to activate AMPK through modulation of this auto-regulatory mechanism, a HTS was performed against an inactive, truncated AMPK- $\alpha$ construct containing only the $\alpha-\mathrm{KD}$ and $\alpha$-AID. The iminothiazolidinone PT-1 was discovered (Figure 3) [113] and its optimization led to the identification of C24 (Figure 3) [114]. PT-1 allosterically stimulates inactive truncated AMPK- $\alpha$ construct and activates full AMPK heterotrimers by antagonizing auto-inhibition of the $\alpha$-KD. It was proposed that PT-1 antagonizes the auto-inhibitory conformation of AMPK$\alpha$ by binding in the cleft between AMPK- $\alpha$ AID and AMPK- $\alpha$ KD [113]. In intact cells, this compound was shown to stimulate AMPK signaling without any significant change in cellular energy charge. However, recent work suggest that PT1 action on AMPK is indirect via inhibition of the respiratory chain and consequent increase in cellular AMP/ATP ratio [115]. In line with the notion that PT-1 is an indirect activator, PT-1 failed to activate AMPK complexes containing AMP-insensitive AMPK- $\gamma 1$ R299G mutant [115]. 
The bi-quinoline compound JJO-1 (Figure 3) was shown to allosterically activate complexes containing the $\gamma 1$ - and $\gamma 2$-isoforms only at low ATP concentrations [116]. JJO-1 has no effect on the protection against AMPK- $\alpha$ Thr172 dephosphorylation and does not synergize with AMP on the allosteric activation of AMPK. Intriguingly, JJO-1 allosterically activates AMPK independently of all identified effector domains, $\alpha$-AID, $\beta$-GBD and $\gamma$-nucleotide-binding sites. These findings suggest that alternate modes of allosteric activation exist and further studies are required to gain insight into the molecular details of JJO-1 action. Hence, other binding sites besides the ADaM site could impact isoform selectivity and highlights the complex cross-talk between binding sites on AMPK.

\section{5-4- Direct allosteric inhibition of AMPK}

The dihydroxyquinoline drug MT47-100 belongs to a novel class of compounds with dual AMPK regulatory properties (Figure 3). It acts simultaneously as an allosteric activator of AMPK complexes containing the $\beta 1$-isoform and an allosteric inhibitor of AMPK complexes containing the $\beta 2$-isoform [117]. MT47-100 activates all AMPK $\beta 1$-containing complexes and this activation is dependent on the $\beta 1-G B D$ and phosphorylation of AMPK $\beta 1$ Ser108. At the opposite, MT47-100 directly inhibits all AMPK $\beta 2$-containing complexes through a $\beta 2-G B D$ allosteric site. Three non-conserved residues within the $\beta$-GBD determine the agonistic/antagonistic properties of MT47-100: Phe82, Tyr92, and Leu93 in AMPK $\beta 1$ and the corresponding residues Ile81, Phe91, and Ile92 in AMPK $\beta 2$. The therapeutic potential of this allosteric inhibitor has been demonstrated on glucose-stimulated insulin secretion (GSIS) from pancreatic $\beta$ cells. Whereas MT47-100 increased GSIS from wild-type isolated mouse islets, MT47-100-mediated effect was lost in islets from AMPK $\beta 2$ knockout mice [117]. These findings provide novel insight into the development of direct AMPK inhibitors by demonstrating that AMPK inhibition with small molecules is possible. The use of pharmacological AMPK inhibitors could be beneficial in some disease settings including obesity and neurodegenerative diseases [118, 119].

\section{6- Challenges to small AMPK activators}

The past decade witnessed successful development of therapeutically useful small molecule direct AMPK activators, powered by tremendous progress in both academic and industrial settings. Existing results to date offer encouragement to further pursue research on AMPK as 
a drug target for the treatment of diseases associated with metabolic syndrome [107, 108, 111]. However, while using small molecule AMPK activators to treat a number of human pathologies appears now feasible, some challenging questions might serve as directions for future development of subtype- or tissue-selective AMPK activators and for improving therapeutic applicability.

First, a central challenge is the complexity related to the distinct combinations of the AMPK subunit isoforms in different tissues and species with distinct regulatory properties and functions. Characterization of the distribution of AMPK heterotrimeric complexes in humans and relevant preclinical models appears critical for both therapeutic and drug discovery purposes. Another important determinant of AMPK action is the subcellular localization of the different isoform combinations. Indeed, there is emerging evidence showing that AMPK isoform selectivity to specific substrates comes from their distinct subcellular localizations, rather than their intrinsic specificity [120]. In addition, localization of AMPK at cellular organelle membranes might also play a role in sensitizing AMPK to allosteric ligands [47]. Thus, more knowledge needs to be gained to further understand the multifaceted regulation and distinct function of AMPK complexes.

Second, the phosphorylation events (e.g., $\alpha$-Thr172 and $\beta$-Ser108) needed for AMPK activation by small molecules binding at the ADaM or other sites remains unclear. Within the $\beta$-GBD, phosphorylation of $\beta 1-S e r 108$ was shown to be required for the activation by small molecules binding in the ADaM site, such as salicylate, A-769662 and 991 [82, 87, 95]. In contrast to $\beta 1$-Ser108, phosphorylation of $\beta 2$-Ser108 is not required for AMPK activation by 991 [121], reflecting subtle changes between the $\beta 1$ and $\beta 2$ subunits in the topology of the $\beta$ $\mathrm{GBD} / \alpha-\mathrm{KD}$ interface in interaction with the activating ligand in the ADaM site. It is known that $\beta 1$ - and $\beta 2-G B D$ adopt different docking onto the $\alpha$-KD. In addition, presence of different amino acids near the $\mathrm{ADaM}$ site between the two $\beta$-isoforms may explain why some of the small molecule activators (e.g., benzimidazole derivatives) are able to activate either $\beta 1$-containing or both $\beta 1$ - and $\beta 2$-containing AMPK isoforms [78]. Consistently, generation of chimeras in which nonconserved amino acids proximal to this interface have been swapped from $\beta 1$ to $\beta 2$ leads to altered ligand specificity [81]. Crystal structure of a $\beta 2$-containing isoform that contains a bound ligand at the $\mathrm{ADaM}$ site will help to better understand the molecular basis of these differences and may bring novel knowledge on the pharmacological regulation of AMPK. This information might be useful to design novel isoform or tissueselective compounds minimizing unwanted side effects. 
Third, it was originally reported that $\beta 1-\operatorname{Ser} 108$ is an autophosphorylation site [122], but it was recently reported as a substrate for ULK1 under conditions associated with elevated AMP [47]. In an aspect relevant to therapeutics, these findings are significant given the importance of this post-translational modification in the mechanism of action of most AMPK synthetic activators and could impact on AMPK drug sensitization independently of autophosphorylation. Interestingly, ULK1 phosphorylation of Ser108 was shown to be specific to the AMPK $\beta 1$-isoform due to divergence in the sequence surrounding Ser108 in the $\beta 2$-isoform [47]. It is not known whether other kinases can phosphorylate $\beta 2-$ Ser108.

Fourth, an exception for the requirement of both $\alpha$-Thr172 and $\beta$-Ser108 phosphorylation is synergistic activation of "naive" unphosphorylated AMPK with compounds binding simultaneously at the ADaM site and $\gamma$ subunit (e.g., A-769662 or 991 and AMP, respectively) as shown in cell-free essays [121-123]. Binding of small molecule in the ADaM site appears to be sufficient to stabilize the activation loop in an active conformation [121]. Interestingly, combination of A-769662 with $\mathrm{C} 2$ also resulted in a synergistic allosteric activation of AMPK bypassing the need for AMPK- $\alpha$ Thr172 phosphorylation [85]. These findings have important implications for development of AMPK-targeting therapeutics and point to possible combinatorial therapies based on synergistic activation of AMPK by direct small molecule allosteric activators independent of AMP and in the absence of upstream phosphorylation (e.g., due to genetic loss or dowregulation of LKB1 signaling [96, 124]). Discovery of a mechanism that induces AMPK drug sensitization independently of autophosphorylation also provides a potential strategy to treat non-small-cell lung and cervical carcinomas, associated with genetic loss of LKB1. However, whether phosphorylation of Thr172 is absolutely required for AMPK signalling in intact cells remains controversial. While Dite et al. reported that combination of A-769662 and phenformin can trigger AMPK cellular signaling independently of $\alpha$-Thr172 phosphorylation [47], Willows et al. failed to activate AMPK signaling in the presence of 991 and 2-deoxyglucose in cells lacking both LKB1 and CaMKK2 [121].

Fifth, while small molecule AMPK activators hold promise for the treatment of a number of human pathologies, concerns about adverse effects of systemic and chronic AMPK activation were raised by studies from naturally occurring single point mutations within the human PRKAG2 gene [125, 126]. These mutations have been associated with increased basal activity of AMPK and are associated with deleterious metabolic cardiac phenotype and hypertrophy. In addition, a genetic mouse model with analogous mutation showed hyperphagia, obesity and 
impaired $\beta$-cell function, questioning the safety of chronic and generalized AMPK activators [118]. Henceforth, establishing efficacy and safety would be essential before AMPK activators would be appropriate for introduction into clinical studies. The potential cardiac safety concerns associated with chronic systemic AMPK activation with MK-8722 have been recently evalutated in rhesus monkeys dosed for up to 8 months [111]. Although increased cardiac glycogen content and hypertrophy was observed but without any changes in electrocardiogram and apparent functional cardiac sequelae, any safety issues associated with AMPK activators remains to be carefully determined in phase I trials. However, the exciting possibility of safe AMPK-driven therapeutics is encouraged by the recently reported advancement and successful completion of phase I trials for two novel small molecule AMPK activators, PXL770 and O304, from Poxel SA and Betagenon AB, respectively [127, 128].

Sixth, significant progress has been made during the last few years regarding the molecular mechanisms underlying the activation of AMPK and this should aid to develop more potent and specific compounds. Information from crystallographic structures combined with computer-based drug design hold promise as a rational approach for discovering isoformspecific small molecule AMPK activators [129, 130]. Identification of novel $\beta 1$-selective AMPK activators by virtual screening using molecular docking was recently reported [131] and holds promise on structure-based design of novel isoform-selective AMPK activators. In addition, improvement of screening methods based on the measure of direct allosteric activation, protection from dephosphorylation or a combination of both can contribute to fasten the identification of new hits [73, 74, 132]. Also, the use of specially-configured biosensors to monitor AMPK activation or conformational changes induced by ligands opens possibilities for identification and characterization of AMPK activators in cell-based assays [133].

\section{7- Conclusion}

Given the pleiotropic action of AMPK signaling on many cellular processes (e.g., increase glucose uptake in skeletal muscle), AMPK has gained much attention as a therapeutic target and there has been a major drive to develop pharmacological activators. The first described pharmacological AMPK activator was the pro-drug AICAR, metabolized into ZMP to mimick the allosteric effects of AMP on the AMPK system owing to its structural analogy with the adenine nucleotide. However, its therapeutic use in humans have so far been inconclusive, given to its relatively high threshold for AMPK activation in skeletal muscle [134]. In 2006, discovery of the first direct AMPK activator, A-769662, provided a novel insight into the 
development of direct AMPK activators by demonstrating that AMPK activation with nonnucleotide ligands was possible [75]. Several new direct AMPK activators have been reported (Figure 3). They exhibit different mechanisms of action through binding to a novel allosteric site formed between the small lobe of the $\alpha-\mathrm{KD}$ and the $\beta$-GBD (ADaM site) or a site located within the solvent-accessible core of the AMPK- $\gamma$ subunit. Interestingly, combination strategies involving compounds binding at these different sites resulted in a synergistic effect on the phosphorylation of AMPK and physiological effects in intact cells [71, 96, 135-138]. These findings are highly relevant from a pharmaceutical point of view for the development of combined treatment of various AMPK agonists such as direct small molecule AMPK activators and the indirect AMPK activator metformin. These combinatorial treatments would be of value to enhance AMPK activation in patients and could help to reduce the amount of drugs administrated for a better tolerability and efficacy. While some small molecules are potent pan-activators for all 12 heterotrimeric AMPK complexes, other show isoform-specific activation for AMPK complexes containing the $\alpha 1$ - or $\beta 1$-isoforms. These findings indicate the possibility of developing isoform-selective AMPK activators for tissue-specific therapeutic interventions. For instance, one interesting therapeutic aspect will be to target the AMPK $\alpha 2 \beta 2 \gamma 3$ heterotrimer which is specifically expressed in skeletal muscle and is predominantly activated by exercise compared to other AMPK heterotrimers [64] and thus, limit potential adverse effect on cardiac hypertrophy [111].

In conclusion, there has been a dramatic progress over the last few years in the development of direct small molecule AMPK activators and in the understanding of their mechanism of action. The ultimate challenge will be to translate the promising therapeutic findings from pre-clinical animal studies into practical clinical applications.

\section{REFERENCES}

[1] D.G. Hardie, F.A. Ross, S.A. Hawley, AMP-Activated Protein Kinase: A Target for Drugs both Ancient and Modern, Chem Biol 19(10) (2012) 1222-36.

[2] D.G. Hardie, M.L. Ashford, AMPK: regulating energy balance at the cellular and whole body levels, Physiology (Bethesda) 29(2) (2014) 99-107.

[3] W.W. Winder, D.G. Hardie, AMP-activated protein kinase, a metabolic master switch: possible roles in type 2 diabetes, The American journal of physiology 277(1 Pt 1) (1999) E1-10.

[4] R. Kjobsted, A.J. Pedersen, J.R. Hingst, R. Sabaratnam, J.B. Birk, J.M. Kristensen, K. Hojlund, J.F. Wojtaszewski, Intact Regulation of the AMPK Signaling Network in Response to Exercise and Insulin in Skeletal Muscle of Male Patients With Type 2 Diabetes: Illumination of AMPK Activation in Recovery From Exercise, Diabetes 65(5) (2016) 1219-30. 
[5] D.G. Hardie, S.C. Lin, AMP-activated protein kinase - not just an energy sensor, F1000Res 6 (2017) 1724.

[6] S.C. Lin, D.G. Hardie, AMPK: Sensing Glucose as well as Cellular Energy Status, Cell Metab (2017).

[7] D.G. Hardie, B.E. Schaffer, A. Brunet, AMPK: An Energy-Sensing Pathway with Multiple Inputs and Outputs, Trends Cell Biol 26(3) (2016) 190-201.

[8] C.S. Zhang, S.A. Hawley, Y. Zong, M. Li, Z. Wang, A. Gray, T. Ma, J. Cui, J.W. Feng, M. Zhu, Y.Q. Wu, T.Y. Li, Z. Ye, S.Y. Lin, H. Yin, H.L. Piao, D.G. Hardie, S.C. Lin, Fructose-1,6-bisphosphate and aldolase mediate glucose sensing by AMPK, Nature 548(7665) (2017) 112-116.

[9] E.A. Day, R.J. Ford, G.R. Steinberg, AMPK as a Therapeutic Target for Treating Metabolic Diseases, Trends Endocrinol Metab 28(8) (2017) 545-560.

[10] D. Garcia, R.J. Shaw, AMPK: Mechanisms of Cellular Energy Sensing and Restoration of Metabolic Balance, Mol Cell 66(6) (2017) 789-800.

[11] M.D. Fullerton, AMP-activated protein kinase and its multifaceted regulation of hepatic metabolism, Curr Opin Lipidol 27(2) (2016) 172-80.

[12] I.P. Salt, D.G. Hardie, AMP-Activated Protein Kinase: An Ubiquitous Signaling Pathway With Key Roles in the Cardiovascular System, Circ Res 120(11) (2017) 1825-1841.

[13] T. Lang, L. Yu, Q. Tu, J. Jiang, Z. Chen, Y. Xin, G. Liu, S. Zhao, Molecular cloning, genomic organization, and mapping of PRKAG2, a heart abundant gamma2 subunit of 5'-AMP-activated protein kinase, to human chromosome 7q36, Genomics 70(2) (2000) 258-63.

[14] K. Pinter, R.T. Grignani, G. Czibik, H. Farza, H. Watkins, C. Redwood, Embryonic expression of AMPK gamma subunits and the identification of a novel gamma2 transcript variant in adult heart, J Mol Cell Cardiol 53(3) (2012) 342-9.

[15] S.A. Hawley, J. Boudeau, J.L. Reid, K.J. Mustard, L. Udd, T.P. Makela, D.R. Alessi, D.G. Hardie, Complexes between the LKB1 tumor suppressor, STRAD alpha/beta and M025 alpha/beta are upstream kinases in the AMP-activated protein kinase cascade, J Biol 2(4) (2003) 28.

[16] A. Woods, S.R. Johnstone, K. Dickerson, F.C. Leiper, L.G. Fryer, D. Neumann, U. Schlattner, T. Wallimann, M. Carlson, D. Carling, LKB1 is the upstream kinase in the AMP-activated protein kinase cascade, Curr Biol 13(22) (2003) 2004-8.

[17] R.J. Shaw, M. Kosmatka, N. Bardeesy, R.L. Hurley, L.A. Witters, R.A. DePinho, L.C. Cantley, The tumor suppressor LKB1 kinase directly activates AMP-activated kinase and regulates apoptosis in response to energy stress, Proc Natl Acad Sci U S A 101(10) (2004) 3329-35.

[18] S.A. Hawley, D.A. Pan, K.J. Mustard, L. Ross, J. Bain, A.M. Edelman, B.G. Frenguelli, D.G. Hardie, Calmodulin-dependent protein kinase kinase-beta is an alternative upstream kinase for AMP-activated protein kinase, Cell Metab 2(1) (2005) 9-19.

[19] A. Woods, K. Dickerson, R. Heath, S.P. Hong, M. Momcilovic, S.R. Johnstone, M. Carlson, D. Carling, $\mathrm{Ca} 2+$ /calmodulin-dependent protein kinase kinase-beta acts upstream of AMP-activated protein kinase in mammalian cells, Cell Metab 2(1) (2005) 21-33.

[20] R.L. Hurley, K.A. Anderson, J.M. Franzone, B.E. Kemp, A.R. Means, L.A. Witters, The Ca2+/calmodulindependent protein kinase kinases are AMP-activated protein kinase kinases, J Biol Chem 280(32) (2005) 29060-6.

[21] S.M. Jeon, Regulation and function of AMPK in physiology and diseases, Exp Mol Med 48(7) (2016) e245.

[22] K. Sakamoto, A. McCarthy, D. Smith, K.A. Green, D. Grahame Hardie, A. Ashworth, D.R. Alessi, Deficiency of LKB1 in skeletal muscle prevents AMPK activation and glucose uptake during contraction, EMBO J 24(10) (2005) 1810-20.

[23] K. Sakamoto, E. Zarrinpashneh, G.R. Budas, A.C. Pouleur, A. Dutta, A.R. Prescott, J.L. Vanoverschelde, A. Ashworth, A. Jovanovic, D.R. Alessi, L. Bertrand, Deficiency of LKB1 in heart prevents ischemia-mediated activation of AMPKalpha2 but not AMPKalpha1, Am J Physiol Endocrinol Metab 290(5) (2006) E780-8.

[24] M. Xie, D. Zhang, J.R. Dyck, Y. Li, H. Zhang, M. Morishima, D.L. Mann, G.E. Taffet, A. Baldini, D.S. Khoury, M.D. Schneider, A pivotal role for endogenous TGF-beta-activated kinase-1 in the LKB1/AMP-activated protein kinase energy-sensor pathway, Proc Natl Acad Sci U S A 103(46) (2006) 17378-83.

[25] G. Herrero-Martin, M. Hoyer-Hansen, C. Garcia-Garcia, C. Fumarola, T. Farkas, A. Lopez-Rivas, M. Jaattela, TAK1 activates AMPK-dependent cytoprotective autophagy in TRAIL-treated epithelial cells, EMBO J 28(6) (2009) 677-85.

[26] S. Inokuchi-Shimizu, E.J. Park, Y.S. Roh, L. Yang, B. Zhang, J. Song, S. Liang, M. Pimienta, K. Taniguchi, X. Wu, K. Asahina, W. Lagakos, M.R. Mackey, S. Akira, M.H. Ellisman, D.D. Sears, J.M. Olefsky, M. Karin, D.A. Brenner, E. Seki, TAK1-mediated autophagy and fatty acid oxidation prevent hepatosteatosis and tumorigenesis, J Clin Invest 124(8) (2014) 3566-78. 
[27] L. Garcia-Haro, M.A. Garcia-Gimeno, D. Neumann, M. Beullens, M. Bollen, P. Sanz, The PP1-R6 protein phosphatase holoenzyme is involved in the glucose-induced dephosphorylation and inactivation of AMPactivated protein kinase, a key regulator of insulin secretion, in MIN6 beta cells, FASEB J 24(12) (2010) 5080-91.

[28] B.K. Joseph, H.Y. Liu, J. Francisco, D. Pandya, M. Donigan, C. Gallo-Ebert, C. Giordano, A. Bata, J.T. Nickels, Jr., Inhibition of AMP Kinase by the Protein Phosphatase 2A Heterotrimer, PP2APpp2r2d, J Biol Chem 290(17) (2015) 10588-98.

[29] L. Chen, Z.H. Jiao, L.S. Zheng, Y.Y. Zhang, S.T. Xie, Z.X. Wang, J.W. Wu, Structural insight into the autoinhibition mechanism of AMP-activated protein kinase, Nature 459(7250) (2009) 1146-9.

[30] L. Chen, F.J. Xin, J. Wang, J. Hu, Y.Y. Zhang, S. Wan, L.S. Cao, C. Lu, P. Li, S.F. Yan, D. Neumann, U. Schlattner, B. Xia, Z.X. Wang, J.W. Wu, Conserved regulatory elements in AMPK, Nature 498(7453) (2013) E8-10.

[31] F.J. Xin, J. Wang, R.Q. Zhao, Z.X. Wang, J.W. Wu, Coordinated regulation of AMPK activity by multiple elements in the alpha-subunit, Cell Res 23(10) (2013) 1237-40.

[32] R.L. Hurley, L.K. Barre, S.D. Wood, K.A. Anderson, B.E. Kemp, A.R. Means, L.A. Witters, Regulation of AMP-activated protein kinase by multisite phosphorylation in response to agents that elevate cellular cAMP, J Biol Chem 281(48) (2006) 36662-72.

[33] N. Djouder, R.D. Tuerk, M. Suter, P. Salvioni, R.F. Thali, R. Scholz, K. Vaahtomeri, Y. Auchli, H. Rechsteiner, R.A. Brunisholz, B. Viollet, T.P. Makela, T. Wallimann, D. Neumann, W. Krek, PKA phosphorylates and inactivates AMPKalpha to promote efficient lipolysis, The EMBO journal 29(2) (2010) 469-81.

[34] S.A. Hawley, F.A. Ross, G.J. Gowans, P. Tibarewal, N.R. Leslie, D.G. Hardie, Phosphorylation by Akt within the ST loop of AMPK-alpha1 down-regulates its activation in tumour cells, The Biochemical journal 459(2) (2014) 275-87.

[35] S. Horman, D. Vertommen, R. Heath, D. Neumann, V. Mouton, A. Woods, U. Schlattner, T. Wallimann, D. Carling, L. Hue, M.H. Rider, Insulin antagonizes ischemia-induced Thr172 phosphorylation of AMPactivated protein kinase alpha-subunits in heart via hierarchical phosphorylation of Ser485/491, J Biol Chem 281(9) (2006) 5335-40.

[36] Y. Dagon, E. Hur, B. Zheng, K. Wellenstein, L.C. Cantley, B.B. Kahn, p70S6 kinase phosphorylates AMPK on serine 491 to mediate leptin's effect on food intake, Cell Metab 16(1) (2012) 104-12.

[37] T. Suzuki, D. Bridges, D. Nakada, G. Skiniotis, S.J. Morrison, J.D. Lin, A.R. Saltiel, K. Inoki, Inhibition of AMPK catabolic action by GSK3, Mol Cell 50(3) (2013) 407-19.

[38] H.R. Heathcote, S.J. Mancini, A. Strembitska, K. Jamal, J.A. Reihill, T.M. Palmer, G.W. Gould, I.P. Salt, Protein kinase C phosphorylates AMP-activated protein kinase alpha1 Ser487, The Biochemical journal 473(24) (2016) 4681-4697.

[39] K.A. Coughlan, R.J. Valentine, B.S. Sudit, K. Allen, Y. Dagon, B.B. Kahn, N.B. Ruderman, A.K. Saha, PKD1 Inhibits AMPKalpha2 through Phosphorylation of Serine 491 and Impairs Insulin Signaling in Skeletal Muscle Cells, J Biol Chem 291(11) (2016) 5664-75.

[40] C.T. Pineda, S. Ramanathan, K. Fon Tacer, J.L. Weon, M.B. Potts, Y.H. Ou, M.A. White, P.R. Potts, Degradation of AMPK by a cancer-specific ubiquitin ligase, Cell 160(4) (2015) 715-28.

[41] I.K. Vila, Y. Yao, G. Kim, W. Xia, H. Kim, S.J. Kim, M.K. Park, J.P. Hwang, E. Gonzalez-Billalabeitia, M.C. Hung, S.J. Song, M.S. Song, A UBE20-AMPKalpha2 Axis that Promotes Tumor Initiation and Progression Offers Opportunities for Therapy, Cancer Cell 31(2) (2017) 208-224.

[42] N. Kazgan, T. Williams, L.J. Forsberg, J.E. Brenman, Identification of a nuclear export signal in the catalytic subunit of AMP-activated protein kinase, Mol Biol Cell 21(19) (2010) 3433-42.

[43] I. Salt, J.W. Celler, S.A. Hawley, A. Prescott, A. Woods, D. Carling, D.G. Hardie, AMP-activated protein kinase: greater AMP dependence, and preferential nuclear localization, of complexes containing the alpha2 isoform, Biochem J 334 ( Pt 1) (1998) 177-87.

[44] S.M. Warden, C. Richardson, J. O'Donnell, Jr., D. Stapleton, B.E. Kemp, L.A. Witters, Post-translational modifications of the beta-1 subunit of AMP-activated protein kinase affect enzyme activity and cellular localization, Biochem J 354(Pt 2) (2001) 275-83.

[45] J.S. Oakhill, Z.P. Chen, J.W. Scott, R. Steel, L.A. Castelli, N. Ling, S.L. Macaulay, B.E. Kemp, beta-Subunit myristoylation is the gatekeeper for initiating metabolic stress sensing by AMP-activated protein kinase (AMPK), Proc Natl Acad Sci U S A 107(45) (2010) 19237-41.

[46] J. Liang, Z.X. Xu, Z. Ding, Y. Lu, Q. Yu, K.D. Werle, G. Zhou, Y.Y. Park, G. Peng, M.J. Gambello, G.B. Mills, Myristoylation confers noncanonical AMPK functions in autophagy selectivity and mitochondrial surveillance, Nat Commun 6 (2015) 7926. 
[47] T.A. Dite, N.X.Y. Ling, J.W. Scott, A. Hoque, S. Galic, B.L. Parker, K.R.W. Ngoei, C.G. Langendorf, M.T. O'Brien, M. Kundu, B. Viollet, G.R. Steinberg, K. Sakamoto, B.E. Kemp, J.S. Oakhill, The autophagy initiator ULK1 sensitizes AMPK to allosteric drugs, Nat Commun 8(1) (2017) 571.

[48] S.B. Jorgensen, J.N. Nielsen, J.B. Birk, G.S. Olsen, B. Viollet, F. Andreelli, P. Schjerling, S. Vaulont, D.G. Hardie, B.F. Hansen, E.A. Richter, J.F. Wojtaszewski, The alpha2-5'AMP-activated protein kinase is a site 2 glycogen synthase kinase in skeletal muscle and is responsive to glucose loading, Diabetes 53(12) (2004) 3074-81.

[49] L. Bultot, B. Guigas, A. Von Wilamowitz-Moellendorff, L. Maisin, D. Vertommen, N. Hussain, M. Beullens, J.J. Guinovart, M. Foretz, B. Viollet, K. Sakamoto, L. Hue, M.H. Rider, AMP-activated protein kinase phosphorylates and inactivates liver glycogen synthase, Biochem J 443(1) (2012) 193-203.

[50] G. Polekhina, A. Gupta, B.J. Michell, B. van Denderen, S. Murthy, S.C. Feil, I.G. Jennings, D.J. Campbell, L.A. Witters, M.W. Parker, B.E. Kemp, D. Stapleton, AMPK beta subunit targets metabolic stress sensing to glycogen, Curr Biol 13(10) (2003) 867-71.

[51] A. Koay, B. Woodcroft, E.J. Petrie, H. Yue, S. Emanuelle, M. Bieri, M.F. Bailey, M. Hargreaves, J.T. Park, K.H. Park, S. Ralph, D. Neumann, D. Stapleton, P.R. Gooley, AMPK beta subunits display isoform specific affinities for carbohydrates, FEBS Lett 584(15) (2010) 3499-503.

[52] Y. Oligschlaeger, M. Miglianico, D. Chanda, R. Scholz, R.F. Thali, R. Tuerk, D.I. Stapleton, P.R. Gooley, D. Neumann, The recruitment of AMP-activated protein kinase to glycogen is regulated by autophosphorylation, J Biol Chem 290(18) (2015) 11715-28.

[53] H. Xu, N.T. Frankenberg, G.D. Lamb, P.R. Gooley, D.I. Stapleton, R.M. Murphy, When phosphorylated at Thr148, the beta2-subunit of AMP-activated kinase does not associate with glycogen in skeletal muscle, Am J Physiol Cell Physiol 311(1) (2016) C35-42.

[54] H. Sakoda, M. Fujishiro, J. Fujio, N. Shojima, T. Ogihara, A. Kushiyama, Y. Fukushima, M. Anai, H. Ono, M. Kikuchi, N. Horike, A.Y. Viana, Y. Uchijima, H. Kurihara, T. Asano, Glycogen debranching enzyme association with beta-subunit regulates AMP-activated protein kinase activity, Am J Physiol Endocrinol Metab 289(3) (2005) E474-81.

[55] J.S. Oakhill, R. Steel, Z.P. Chen, J.W. Scott, N. Ling, S. Tam, B.E. Kemp, AMPK is a direct adenylate charge-regulated protein kinase, Science 332(6036) (2011) 1433-5.

[56] B. Xiao, R. Heath, P. Saiu, F.C. Leiper, P. Leone, C. Jing, P.A. Walker, L. Haire, J.F. Eccleston, C.T. Davis, S.R. Martin, D. Carling, S.J. Gamblin, Structural basis for AMP binding to mammalian AMP-activated protein kinase, Nature 449(7161) (2007) 496-500.

[57] G.J. Gowans, S.A. Hawley, F.A. Ross, D.G. Hardie, AMP is a true physiological regulator of AMPactivated protein kinase by both allosteric activation and enhancing net phosphorylation, Cell Metab 18(4) (2013) 556-66.

[58] B. Xiao, M.J. Sanders, E. Underwood, R. Heath, F.V. Mayer, D. Carmena, C. Jing, P.A. Walker, J.F. Eccleston, L.F. Haire, P. Saiu, S.A. Howell, R. Aasland, S.R. Martin, D. Carling, S.J. Gamblin, Structure of mammalian AMPK and its regulation by ADP, Nature 472(7342) (2011) 230-3.

[59] F.A. Ross, T.E. Jensen, D.G. Hardie, Differential regulation by AMP and ADP of AMPK complexes containing different gamma subunit isoforms, Biochem J 473(2) (2016) 189-99.

[60] Y.L. Zhang, H. Guo, C.S. Zhang, S.Y. Lin, Z. Yin, Y. Peng, H. Luo, Y. Shi, G. Lian, C. Zhang, M. Li, Z. Ye, J. Ye, J. Han, P. Li, J.W. Wu, S.C. Lin, AMP as a low-energy charge signal autonomously initiates assembly of AXINAMPK-LKB1 complex for AMPK activation, Cell Metab 18(4) (2013) 546-55.

[61] C.S. Zhang, B. Jiang, M. Li, M. Zhu, Y. Peng, Y.L. Zhang, Y.Q. Wu, T.Y. Li, Y. Liang, Z. Lu, G. Lian, Q. Liu, H. Guo, Z. Yin, Z. Ye, J. Han, J.W. Wu, H. Yin, S.Y. Lin, S.C. Lin, The lysosomal v-ATPase-Ragulator complex is a common activator for AMPK and mTORC1, acting as a switch between catabolism and anabolism, Cell Metab 20(3) (2014) 526-40.

[62] J.F. Wojtaszewski, J.B. Birk, C. Frosig, M. Holten, H. Pilegaard, F. Dela, 5'AMP activated protein kinase expression in human skeletal muscle: effects of strength training and type 2 diabetes, J Physiol 564(Pt 2) (2005) 563-73.

[63] J.T. Treebak, J.B. Birk, B.F. Hansen, G.S. Olsen, J.F. Wojtaszewski, A-769662 activates AMPK beta1containing complexes but induces glucose uptake through a PI3-kinase-dependent pathway in mouse skeletal muscle, Am J Physiol Cell Physiol 297(4) (2009) C1041-52.

[64] J.B. Birk, J.F. Wojtaszewski, Predominant alpha2/beta2/gamma3 AMPK activation during exercise in human skeletal muscle, J Physiol 577(Pt 3) (2006) 1021-32.

[65] E.J. Kurth-Kraczek, M.F. Hirshman, L.J. Goodyear, W.W. Winder, 5' AMP-activated protein kinase activation causes GLUT4 translocation in skeletal muscle, Diabetes 48(8) (1999) 1667-71.

[66] J.T. Treebak, C. Pehmoller, J.M. Kristensen, R. Kjobsted, J.B. Birk, P. Schjerling, E.A. Richter, L.J. Goodyear, J.F. Wojtaszewski, Acute exercise and physiological insulin induce distinct phosphorylation signatures on TBC1D1 and TBC1D4 proteins in human skeletal muscle, J Physiol 592(2) (2014) 351-75. 
[67] J. Wu, D. Puppala, X. Feng, M. Monetti, A.L. Lapworth, K.F. Geoghegan, Chemoproteomic analysis of intertissue and interspecies isoform diversity of AMP-activated protein kinase (AMPK), J Biol Chem 288(50) (2013) 35904-12.

[68] X. Stephenne, M. Foretz, N. Taleux, G.C. van der Zon, E. Sokal, L. Hue, B. Viollet, B. Guigas, Metformin activates AMP-activated protein kinase in primary human hepatocytes by decreasing cellular energy status, Diabetologia 54(12) (2011) 3101-10.

[69] E.P. Brass, C.L. Hoppel, Mitochondria as targets of drug toxicity: Lessons from the R118 phase I experience, Clin Pharmacol Ther 98(5) (2015) 464-6.

[70] C.C. Low Wang, J.L. Galinkin, W.R. Hiatt, Toxicity of a novel therapeutic agent targeting mitochondrial complex I, Clin Pharmacol Ther 98(5) (2015) 551-9.

[71] M. Foretz, S. Hebrard, J. Leclerc, E. Zarrinpashneh, M. Soty, G. Mithieux, K. Sakamoto, F. Andreelli, B. Viollet, Metformin inhibits hepatic gluconeogenesis in mice independently of the LKB1/AMPK pathway via a decrease in hepatic energy state, J Clin Invest 120(7) (2010) 2355-69.

[72] B. Guigas, K. Sakamoto, N. Taleux, S.M. Reyna, N. Musi, B. Viollet, L. Hue, Beyond AICA riboside: in search of new specific AMP-activated protein kinase activators, IUBMB Life 61(1) (2009) 18-26.

[73] S.E. Sinnett, J.E. Brenman, Past strategies and future directions for identifying AMP-activated protein kinase (AMPK) modulators, Pharmacol Ther 143(1) (2014) 111-8.

[74] J. Kim, J. Shin, J. Ha, Screening methods for AMP-activated protein kinase modulators: a patent review, Expert Opin Ther Pat 25(3) (2015) 261-77.

[75] B. Cool, B. Zinker, W. Chiou, L. Kifle, N. Cao, M. Perham, R. Dickinson, A. Adler, G. Gagne, R. Iyengar, G. Zhao, K. Marsh, P. Kym, P. Jung, H.S. Camp, E. Frevert, Identification and characterization of a small molecule AMPK activator that treats key components of type 2 diabetes and the metabolic syndrome, Cell Metab 3(6) (2006) 403-16.

[76] B. Guigas, B. Viollet, Targeting AMPK: From Ancient Drugs to New Small-Molecule Activators, Exs 107 (2016) 327-350.

[77] J. Kim, G. Yang, Y. Kim, J. Ha, AMPK activators: mechanisms of action and physiological activities, Exp Mol Med 48 (2016) e224.

[78] K.O. Cameron, R.G. Kurumbail, Recent progress in the identification of adenosine monophosphateactivated protein kinase (AMPK) activators, Bioorg Med Chem Lett 26(21) (2016) 5139-5148.

[79] H. Yun, J. Ha, AMP-activated protein kinase modulators: a patent review (2006 - 2010), Expert Opin Ther Pat 21(7) (2011) 983-1005.

[80] R.W. Hunter, M. Foretz, L. Bultot, M.D. Fullerton, M. Deak, F.A. Ross, S.A. Hawley, N. Shpiro, B. Viollet, D. Barron, B.E. Kemp, G.R. Steinberg, D.G. Hardie, K. Sakamoto, Mechanism of action of compound-13: an alpha1-selective small molecule activator of AMPK, Chem Biol 21(7) (2014) 866-79.

[81] M.F. Calabrese, F. Rajamohan, M.S. Harris, N.L. Caspers, R. Magyar, J.M. Withka, H. Wang, K.A. Borzilleri, P.V. Sahasrabudhe, L.R. Hoth, K.F. Geoghegan, S. Han, J. Brown, T.A. Subashi, A.R. Reyes, R.K. Frisbie, J. Ward, R.A. Miller, J.A. Landro, A.T. Londregan, P.A. Carpino, S. Cabral, A.C. Smith, E.L. Conn, K.O. Cameron, X. Qiu, R.G. Kurumbail, Structural basis for AMPK activation: natural and synthetic ligands regulate kinase activity from opposite poles by different molecular mechanisms, Structure 22(8) (2014) 1161-1172.

[82] B. Xiao, M.J. Sanders, D. Carmena, N.J. Bright, L.F. Haire, E. Underwood, B.R. Patel, R.B. Heath, P.A. Walker, S. Hallen, F. Giordanetto, S.R. Martin, D. Carling, S.J. Gamblin, Structural basis of AMPK regulation by small molecule activators, Nat Commun 4 (2013) 3017.

[83] X. Li, L. Wang, X.E. Zhou, J. Ke, P.W. de Waal, X. Gu, M.H. Tan, D. Wang, D. Wu, H.E. Xu, K. Melcher, Structural basis of AMPK regulation by adenine nucleotides and glycogen, Cell Res 25(1) (2015) 50-66.

[84] F.A. Ross, S.A. Hawley, F.R. Auciello, G.J. Gowans, A. Atrih, D.J. Lamont, D.G. Hardie, Mechanisms of Paradoxical Activation of AMPK by the Kinase Inhibitors SU6656 and Sorafenib, Cell Chem Biol 24(7) (2017) 813-824 e4.

[85] C.G. Langendorf, K.R. Ngoei, J.W. Scott, N.X. Ling, S.M. Issa, M.A. Gorman, M.W. Parker, K. Sakamoto, J.S. Oakhill, B.E. Kemp, Structural basis of allosteric and synergistic activation of AMPK by furan-2-phosphonic derivative C2 binding, Nat Commun 7 (2016) 10912.

[86] O. Goransson, A. McBride, S.A. Hawley, F.A. Ross, N. Shpiro, M. Foretz, B. Viollet, D.G. Hardie, K. Sakamoto, Mechanism of action of A-769662, a valuable tool for activation of AMP-activated protein kinase, J Biol Chem 282(45) (2007) 32549-60.

[87] M.J. Sanders, Z.S. Ali, B.D. Hegarty, R. Heath, M.A. Snowden, D. Carling, Defining the mechanism of activation of AMP-activated protein kinase by the small molecule A-769662, a member of the thienopyridone family, J Biol Chem 282(45) (2007) 32539-48. 
[88] S.A. Hawley, F.A. Ross, C. Chevtzoff, K.A. Green, A. Evans, S. Fogarty, M.C. Towler, L.J. Brown, O.A. Ogunbayo, A.M. Evans, D.G. Hardie, Use of cells expressing gamma subunit variants to identify diverse mechanisms of AMPK activation, Cell Metab 11(6) (2010) 554-65.

[89] J.W. Scott, B.J. van Denderen, S.B. Jorgensen, J.E. Honeyman, G.R. Steinberg, J.S. Oakhill, T.J. Iseli, A. Koay, P.R. Gooley, D. Stapleton, B.E. Kemp, Thienopyridone drugs are selective activators of AMP-activated protein kinase beta1-containing complexes, Chem Biol 15(11) (2008) 1220-30.

[90] B. Benziane, M. Bjornholm, L. Lantier, B. Viollet, J.R. Zierath, A.V. Chibalin, AMP-activated protein kinase activator A-769662 is an inhibitor of the $\mathrm{Na(+)-K(+)-ATPase,} \mathrm{Am} \mathrm{J} \mathrm{Physiol} \mathrm{Cell} \mathrm{Physiol} \mathrm{297(6)}$ (2009) C1554-66.

[91] D. Moreno, E. Knecht, B. Viollet, P. Sanz, A769662, a novel activator of AMP-activated protein kinase, inhibits non-proteolytic components of the $26 \mathrm{~S}$ proteasome by an AMPK-independent mechanism, FEBS Lett 582(17) (2008) 2650-4.

[92] Y.C. Lai, S. Kviklyte, D. Vertommen, L. Lantier, M. Foretz, B. Viollet, S. Hallen, M.H. Rider, A smallmolecule benzimidazole derivative that potently activates AMPK to increase glucose transport in skeletal muscle: comparison with effects of contraction and other AMPK activators, Biochem J 460(3) (2014) 36375.

[93] B. Viollet, B. Guigas, J. Leclerc, S. Hebrard, L. Lantier, R. Mounier, F. Andreelli, M. Foretz, AMPactivated protein kinase in the regulation of hepatic energy metabolism: from physiology to therapeutic perspectives, Acta physiologica 196(1) (2009) 81-98.

[94] B.K. Smith, K. Marcinko, E.M. Desjardins, J.S. Lally, R.J. Ford, G.R. Steinberg, Treatment of nonalcoholic fatty liver disease: role of AMPK, Am J Physiol Endocrinol Metab 311(4) (2016) E730-E740.

[95] S.A. Hawley, M.D. Fullerton, F.A. Ross, J.D. Schertzer, C. Chevtzoff, K.J. Walker, M.W. Peggie, D. Zibrova, K.A. Green, K.J. Mustard, B.E. Kemp, K. Sakamoto, G.R. Steinberg, D.G. Hardie, The ancient drug salicylate directly activates AMP-activated protein kinase, Science 336(6083) (2012) 918-22.

[96] N. Boudaba, A. Marion, C. Huet, R. Pierre, B. Viollet, M. Foretz, AMPK Re-Activation Suppresses Hepatic Steatosis but its Downregulation Does Not Promote Fatty Liver Development, EBioMedicine (2018).

[97] F.A. Duca, C.D. Cote, B.A. Rasmussen, M. Zadeh-Tahmasebi, G.A. Rutter, B.M. Filippi, T.K. Lam, Metformin activates a duodenal Ampk-dependent pathway to lower hepatic glucose production in rats, Nat Med 21(5) (2015) 506-11.

[98] R. Mounier, M. Theret, L. Arnold, S. Cuvellier, L. Bultot, O. Goransson, N. Sanz, A. Ferry, K. Sakamoto, M. Foretz, B. Viollet, B. Chazaud, AMPKalpha1 regulates macrophage skewing at the time of resolution of inflammation during skeletal muscle regeneration, Cell Metab 18(2) (2013) 251-64.

[99] S.J. Mancini, A.D. White, S. Bijland, C. Rutherford, D. Graham, E.A. Richter, B. Viollet, R.M. Touyz, T.M. Palmer, I.P. Salt, Activation of AMP-activated protein kinase rapidly suppresses multiple pro-inflammatory pathways in adipocytes including IL-1 receptor-associated kinase-4 phosphorylation, Mol Cell Endocrinol 440 (2017) 44-56.

[100] C. Rutherford, C. Speirs, J.J. Williams, M.A. Ewart, S.J. Mancini, S.A. Hawley, C. Delles, B. Viollet, A.P. Costa-Pereira, G.S. Baillie, I.P. Salt, T.M. Palmer, Phosphorylation of Janus kinase 1 (JAK1) by AMPactivated protein kinase (AMPK) links energy sensing to anti-inflammatory signaling, Sci Signal 9(453) (2016) ra109.

[101] S. Galic, M.D. Fullerton, J.D. Schertzer, S. Sikkema, K. Marcinko, C.R. Walkley, D. Izon, J. Honeyman, Z.P. Chen, B.J. van Denderen, B.E. Kemp, G.R. Steinberg, Hematopoietic AMPK beta1 reduces mouse adipose tissue macrophage inflammation and insulin resistance in obesity, The Journal of clinical investigation 121(12) (2011) 4903-15.

[102] M. Guma, Y. Wang, B. Viollet, R. Liu-Bryan, AMPK Activation by A-769662 Controls IL-6 Expression in Inflammatory Arthritis, PloS one 10(10) (2015) e0140452.

[103] A.S. Kim, E.J. Miller, T.M. Wright, J. Li, D. Qi, K. Atsina, V. Zaha, K. Sakamoto, L.H. Young, A small molecule AMPK activator protects the heart against ischemia-reperfusion injury, Journal of molecular and cellular cardiology 51(1) (2011) 24-32.

[104] A.D. Timmermans, M. Balteau, R. Gelinas, E. Renguet, A. Ginion, C. de Meester, K. Sakamoto, J.L. Balligand, F. Bontemps, J.L. Vanoverschelde, S. Horman, C. Beauloye, L. Bertrand, A-769662 potentiates the effect of other AMP-activated protein kinase activators on cardiac glucose uptake, Am J Physiol Heart Circ Physiol 306(12) (2014) H1619-30.

[105] G. Zadra, C. Photopoulos, S. Tyekucheva, P. Heidari, Q.P. Weng, G. Fedele, H. Liu, N. Scaglia, C. Priolo, E. Sicinska, U. Mahmood, S. Signoretti, N. Birnberg, M. Loda, A novel direct activator of AMPK inhibits prostate cancer growth by blocking lipogenesis, EMBO Mol Med 6(4) (2014) 519-38.

[106] K.O. Cameron, D.W. Kung, A.S. Kalgutkar, R.G. Kurumbail, R. Miller, C.T. Salatto, J. Ward, J.M. Withka, S.K. Bhattacharya, M. Boehm, K.A. Borzilleri, J.A. Brown, M. Calabrese, N.L. Caspers, E. Cokorinos, E.L. Conn, 
M.S. Dowling, D.J. Edmonds, H. Eng, D.P. Fernando, R. Frisbie, D. Hepworth, J. Landro, Y. Mao, F. Rajamohan, A.R. Reyes, C.R. Rose, T. Ryder, A. Shavnya, A.C. Smith, M. Tu, A.C. Wolford, J. Xiao, Discovery and Preclinical Characterization of 6-Chloro-5-[4-(1-hydroxycyclobutyl)phenyl]-1H-indole-3-carboxylic Acid (PF-06409577), a Direct Activator of Adenosine Monophosphate-activated Protein Kinase (AMPK), for the Potential Treatment of Diabetic Nephropathy, J Med Chem 59(17) (2016) 8068-81.

[107] C.T. Salatto, R.A. Miller, K.O. Cameron, E. Cokorinos, A. Reyes, J. Ward, M.F. Calabrese, R.G. Kurumbail, F. Rajamohan, A.S. Kalgutkar, D.A. Tess, A. Shavnya, N.E. Genung, D.J. Edmonds, A. Jatkar, B.S. Maciejewski, M. Amaro, H. Gandhok, M. Monetti, K. Cialdea, E. Bollinger, J.M. Kreeger, T.M. Coskran, A.C. Opsahl, G.G. Boucher, M.J. Birnbaum, P. DaSilva-Jardine, T. Rolph, Selective Activation of AMPK beta1Containing Isoforms Improves Kidney Function in a Rat Model of Diabetic Nephropathy, J Pharmacol Exp Ther 361(2) (2017) 303-311.

[108] E.C. Cokorinos, J. Delmore, A.R. Reyes, B. Albuquerque, R. Kjobsted, N.O. Jorgensen, J.L. Tran, A. Jatkar, K. Cialdea, R.M. Esquejo, J. Meissen, M.F. Calabrese, J. Cordes, R. Moccia, D. Tess, C.T. Salatto, T.M. Coskran, A.C. Opsahl, D. Flynn, M. Blatnik, W. Li, E. Kindt, M. Foretz, B. Viollet, J. Ward, R.G. Kurumbail, A.S. Kalgutkar, J.F.P. Wojtaszewski, K.O. Cameron, R.A. Miller, Activation of Skeletal Muscle AMPK Promotes Glucose Disposal and Glucose Lowering in Non-human Primates and Mice, Cell Metab 25(5) (2017) 1147$1159 \mathrm{e} 10$.

[109] https://www.clinicaltrials.gov/ct2/show/NCT02286882?term=PF-06409577\&rank=1.

[110] R. Willows, N. Navaratnam, A. Lima, J. Read, D. Carling, Effect of different gamma-subunit isoforms on the regulation of AMPK, Biochem J 474(10) (2017) 1741-1754.

[111] R.W. Myers, H.P. Guan, J. Ehrhart, A. Petrov, S. Prahalada, E. Tozzo, X. Yang, M.M. Kurtz, M. Trujillo, D. Gonzalez Trotter, D. Feng, S. Xu, G. Eiermann, M.A. Holahan, D. Rubins, S. Conarello, X. Niu, S.C. Souza, C. Miller, J. Liu, K. Lu, W. Feng, Y. Li, R.E. Painter, J.A. Milligan, H. He, F. Liu, A. Ogawa, D. Wisniewski, R.J. Rohm, L. Wang, M. Bunzel, Y. Qian, W. Zhu, H. Wang, B. Bennet, L. LaFranco Scheuch, G.E. Fernandez, C. Li, M. Klimas, G. Zhou, M. van Heek, T. Biftu, A. Weber, D.E. Kelley, N. Thornberry, M.D. Erion, D.M. Kemp, I.K. Sebhat, Systemic pan-AMPK activator MK-8722 improves glucose homeostasis but induces cardiac hypertrophy, Science 357(6350) (2017) 507-511.

[112] J.E. Gomez-Galeno, Q. Dang, T.H. Nguyen, S.H. Boyer, M.P. Grote, Z. Sun, M. Chen, W.A. Craigo, P.D. van Poelje, D.A. MacKenna, E.E. Cable, P.A. Rolzin, P.D. Finn, B. Chi, D.L. Linemeyer, S.J. Hecker, M.D. Erion, A Potent and Selective AMPK Activator That Inhibits de Novo Lipogenesis, ACS Med Chem Lett 1(9) (2010) 478-82.

[113] T. Pang, Z.S. Zhang, M. Gu, B.Y. Qiu, L.F. Yu, P.R. Cao, W. Shao, M.B. Su, J.Y. Li, F.J. Nan, J. Li, Small molecule antagonizes autoinhibition and activates AMP-activated protein kinase in cells, J Biol Chem 283(23) (2008) 16051-60.

[114] Y.Y. Li, L.F. Yu, L.N. Zhang, B.Y. Qiu, M.B. Su, F. Wu, D.K. Chen, T. Pang, M. Gu, W. Zhang, W.P. Ma, H.W. Jiang, J.Y. Li, F.J. Nan, J. Li, Novel small-molecule AMPK activator orally exerts beneficial effects on diabetic db/db mice, Toxicol Appl Pharmacol 273(2) (2013) 325-34.

[115] T.E. Jensen, F.A. Ross, M. Kleinert, L. Sylow, J.R. Knudsen, G.J. Gowans, D.G. Hardie, E.A. Richter, PT-1 selectively activates AMPK-gamma1 complexes in mouse skeletal muscle, but activates all three gamma subunit complexes in cultured human cells by inhibiting the respiratory chain, Biochem J 467(3) (2015) 461-72.

[116] J.W. Scott, J.S. Oakhill, N.X. Ling, C.G. Langendorf, R.C. Foitzik, B.E. Kemp, O.G. Issinger, ATP sensitive bi-quinoline activator of the AMP-activated protein kinase, Biochem Biophys Res Commun 443(2) (2014) 435-40.

[117] J.W. Scott, S. Galic, K.L. Graham, R. Foitzik, N.X. Ling, T.A. Dite, S.M. Issa, C.G. Langendorf, Q.P. Weng, H.E. Thomas, T.W. Kay, N.C. Birnberg, G.R. Steinberg, B.E. Kemp, J.S. Oakhill, Inhibition of AMP-Activated Protein Kinase at the Allosteric Drug-Binding Site Promotes Islet Insulin Release, Chem Biol 22(6) (2015) 705-11.

[118] A. Yavari, C.J. Stocker, S. Ghaffari, E.T. Wargent, V. Steeples, G. Czibik, K. Pinter, M. Bellahcene, A. Woods, P.B. Martinez de Morentin, C. Cansell, B.Y. Lam, A. Chuster, K. Petkevicius, M.S. Nguyen-Tu, A. Martinez-Sanchez, T.J. Pullen, P.L. Oliver, A. Stockenhuber, C. Nguyen, M. Lazdam, J.F. O'Dowd, P. Harikumar, M. Toth, C. Beall, T. Kyriakou, J. Parnis, D. Sarma, G. Katritsis, D.D. Wortmann, A.R. Harper, L.A. Brown, R. Willows, S. Gandra, V. Poncio, M.J. de Oliveira Figueiredo, N.R. Qi, S.N. Peirson, R.J. McCrimmon, B. Gereben, L. Tretter, C. Fekete, C. Redwood, G.S. Yeo, L.K. Heisler, G.A. Rutter, M.A. Smith, D.J. Withers, D. Carling, E.B. Sternick, J.R. Arch, M.A. Cawthorne, H. Watkins, H. Ashrafian, Chronic Activation of gamma2 AMPK Induces Obesity and Reduces beta Cell Function, Cell Metab 23(5) (2016) 821-36.

[119] M. Domise, V. Vingtdeux, AMPK in Neurodegenerative Diseases, Exs 107 (2016) 153-177.

[120] F.A. Ross, C. MacKintosh, D.G. Hardie, AMP-activated protein kinase: a cellular energy sensor that comes in 12 flavours, FEBS J 283(16) (2016) 2987-3001. 
[121] R. Willows, M.J. Sanders, B. Xiao, B.R. Patel, S.R. Martin, J. Read, J.R. Wilson, J. Hubbard, S.J. Gamblin, D. Carling, Phosphorylation of AMPK by upstream kinases is required for activity in mammalian cells, The Biochemical journal 474(17) (2017) 3059-3073.

[122] J.W. Scott, N. Ling, S.M. Issa, T.A. Dite, M.T. O'Brien, Z.P. Chen, S. Galic, C.G. Langendorf, G.R. Steinberg, B.E. Kemp, J.S. Oakhill, Small molecule drug A-769662 and AMP synergistically activate naive AMPK independent of upstream kinase signaling, Chem Biol 21(5) (2014) 619-27.

[123] B. Viollet, M. Foretz, U. Schlattner, Bypassing AMPK phosphorylation, Chem Biol 21(5) (2014) 567-9. [124] D.B. Shackelford, R.J. Shaw, The LKB1-AMPK pathway: metabolism and growth control in tumour suppression, Nat Rev Cancer 9(8) (2009) 563-75.

[125] E. Blair, C. Redwood, H. Ashrafian, M. Oliveira, J. Broxholme, B. Kerr, A. Salmon, I. Ostman-Smith, H. Watkins, Mutations in the gamma(2) subunit of AMP-activated protein kinase cause familial hypertrophic cardiomyopathy: evidence for the central role of energy compromise in disease pathogenesis, Hum Mol Genet 10(11) (2001) 1215-20.

[126] M.H. Gollob, M.S. Green, A.S. Tang, T. Gollob, A. Karibe, A.S. Ali Hassan, F. Ahmad, R. Lozado, G. Shah, L. Fananapazir, L.L. Bachinski, R. Roberts, Identification of a gene responsible for familial Wolff-ParkinsonWhite syndrome, N Engl J Med 344(24) (2001) 1823-31.

[127] https://www.poxelpharma.com/en_us/product-pipeline/pxl770.

[128] http://betagenon.se/wp-content/uploads/2017/04/Betagenon-0304-2016.pdf.

[129] J. Kim, G. Yang, J. Ha, Targeting of AMP-activated protein kinase: prospects for computer-aided drug design, Expert Opin Drug Discov 12(1) (2017) 47-59.

[130] M. Miglianico, G.A. Nicolaes, D. Neumann, Pharmacological Targeting of AMP-Activated Protein Kinase and Opportunities for Computer-Aided Drug Design, J Med Chem 59(7) (2016) 2879-93.

[131] T. Huang, J. Sun, S. Zhou, J. Gao, Y. Liu, Identification of Direct Activator of Adenosine Monophosphate-Activated Protein Kinase (AMPK) by Structure-Based Virtual Screening and Molecular Docking Approach, Int J Mol Sci 18(7) (2017).

[132] J. Ward, A.R. Reyes, R.G. Kurumbail, Allosteric Modulation of AMPK Enzymatic Activity: In Vitro Characterization, Methods Enzymol 587 (2017) 481-509.

[133] M. Pelosse, C. Cottet-Rousselle, A. Grichine, I. Berger, U. Schlattner, Genetically Encoded Fluorescent Biosensors to Explore AMPK Signaling and Energy Metabolism, Exs 107 (2016) 491-523.

[134] M. Bosselaar, P. Smits, L.J. van Loon, C.J. Tack, Intravenous AICAR during hyperinsulinemia induces systemic hemodynamic changes but has no local metabolic effect, J Clin Pharmacol 51(10) (2011) 144958.

[135] A.J. O'Brien, L.A. Villani, L.A. Broadfield, V.P. Houde, S. Galic, G. Blandino, B.E. Kemp, T. Tsakiridis, P. Muti, G.R. Steinberg, Salicylate activates AMPK and synergizes with metformin to reduce the survival of prostate and lung cancer cells ex vivo through inhibition of de novo lipogenesis, The Biochemical journal 469(2) (2015) 177-87.

[136] S. Ducommun, R.J. Ford, L. Bultot, M. Deak, L. Bertrand, B.E. Kemp, G.R. Steinberg, K. Sakamoto, Enhanced activation of cellular AMPK by dual-small molecule treatment: AICAR and A769662, Am J Physiol Endocrinol Metab 306(6) (2014) E688-96.

[137] R.J. Ford, M.D. Fullerton, S.L. Pinkosky, E.A. Day, J.W. Scott, J.S. Oakhill, A.L. Bujak, B.K. Smith, J.D. Crane, R.M. Blumer, K. Marcinko, B.E. Kemp, H.C. Gerstein, G.R. Steinberg, Metformin and salicylate synergistically activate liver AMPK, inhibit lipogenesis and improve insulin sensitivity, The Biochemical journal 468(1) (2015) 125-32.

[138] L. Bultot, T.E. Jensen, Y.C. Lai, A.L. Madsen, C. Collodet, S. Kviklyte, M. Deak, A. Yavari, M. Foretz, S. Ghaffari, M. Bellahcene, H. Ashrafian, M.H. Rider, E.A. Richter, K. Sakamoto, Benzimidazole derivative small-molecule 991 enhances AMPK activity and glucose uptake induced by AICAR or contraction in skeletal muscle, Am J Physiol Endocrinol Metab 311(4) (2016) E706-E719.

[139] S. Fraser, P. Mount, R. Hill, V. Levidiotis, F. Katsis, D. Stapleton, B.E. Kemp, D.A. Power, Regulation of the energy sensor AMP-activated protein kinase in the kidney by dietary salt intake and osmolality, Am J Physiol Renal Physiol 288(3) (2005) F578-86.

[140] S. Obba, Z. Hizir, L. Boyer, D. Selimoglu-Buet, A. Pfeifer, G. Michel, M.A. Hamouda, D. Goncalves, M. Cerezo, S. Marchetti, S. Rocchi, N. Droin, T. Cluzeau, G. Robert, F. Luciano, B. Robaye, M. Foretz, B. Viollet, L. Legros, E. Solary, P. Auberger, A. Jacquel, The PRKAA1/AMPKalpha1 pathway triggers autophagy during CSF1-induced human monocyte differentiation and is a potential target in CMML, Autophagy 11(7) (2015) 1114-29.

[141] J. Kanellis, R.K. Kandane, D. Etemadmoghadam, S.A. Fraser, P.F. Mount, V. Levidiotis, B.E. Kemp, D.A. Power, Activators of the energy sensing kinase AMPK inhibit random cell movement and chemotaxis in U937 cells, Immunol Cell Biol 84(1) (2006) 6-12. 
[142] D. Sag, D. Carling, R.D. Stout, J. Suttles, Adenosine 5'-monophosphate-activated protein kinase promotes macrophage polarization to an anti-inflammatory functional phenotype, J Immunol 181(12) (2008) 8633-41.

\section{Acknowledgements}

This work was supported by grants from Inserm, CNRS, Université Paris Descartes, Société Francophone du Diabète (SFD) and Fondation pour la Recherche Médicale (FRM) grant number DEQ20150934718. This work was performed within the Département HospitaloUniversitaire (DHU) AUToimmune and HORmonal diseaseS (AUTHORS). S.O. holds a doctoral fellowship from the Région Ile-de-France (CORDDIM).

The authors have no conflict of interest related to this work. 
Table 1: Small molecule AMPK activators and their perspectives in health: in vivo evidence. A summary table of the main in vivo effects of small molecule activators. nt: not tested.

\begin{tabular}{|c|c|c|c|c|c|c|c|}
\hline $\begin{array}{l}\text { Compound } \\
\text { name }\end{array}$ & $\begin{array}{l}\text { Binding } \\
\text { site }\end{array}$ & $\begin{array}{l}\text { Isoform } \\
\text { selectivity }\end{array}$ & $\begin{array}{l}\text { Targeted } \\
\text { tissues }\end{array}$ & Health benefits & $\begin{array}{l}\text { Animal } \\
\text { models }\end{array}$ & Specificity for AMPK & References \\
\hline \multirow[t]{6}{*}{ A-769662 } & \multirow[t]{6}{*}{ ADaM } & \multirow[t]{6}{*}{$\beta 1$} & \multirow[t]{2}{*}{ Liver } & \multirow{2}{*}{$\begin{array}{l}\mathbf{y} \text { Hepatic lipid } \\
\text { accumulation }\end{array}$} & Mice & nt & [75] \\
\hline & & & & & Mice & Liver-specific AMPK KO & {$[96]$} \\
\hline & & & Liver & $\begin{array}{l}\boldsymbol{\lambda} \text { Fatty acids } \\
\text { utilization }\end{array}$ & Rats & nt & {$[75]$} \\
\hline & & & Heart & $\boldsymbol{\lambda}$ Cardioprotection & Mice & $\begin{array}{l}\text { Heart-specific AMPK } \alpha 2 \\
\text { KD }\end{array}$ & {$[103]$} \\
\hline & & & Macrophage & yaI Inflammation & Mice & AMPK $\alpha 1 \mathrm{KO}$ & {$[102]$} \\
\hline & & & Small intestine & $\begin{array}{l}\mathbf{y} \text { ? Hepatic glucose } \\
\text { production }\end{array}$ & Rats & $\begin{array}{l}\text { Ad-DN-AMPK duodenal } \\
\text { infection }\end{array}$ & [97] \\
\hline $\begin{array}{l}\text { PF-06409577 } \\
\text { PF-249 }\end{array}$ & ADaM & $\beta 1$ & Kidney & $\begin{array}{l}\text { y Diabetic } \\
\text { nephropathy }\end{array}$ & Rats & nt & {$[107]$} \\
\hline MT63-78 & ADaM & $\beta 1$ & Prostate & $\begin{array}{l}\text { y Prostate cancer } \\
\text { growth }\end{array}$ & Mice & AMPK $\alpha 2 \mathrm{KO}$ & {$[105]$} \\
\hline GSK621 & ADaM & $\beta 1 / \beta 2$ & $\begin{array}{l}\text { Acute Myeloid } \\
\text { Leukemia cells }\end{array}$ & $\boldsymbol{\lambda}$ Cancer cell death & Mice & AMPK $\alpha 1$ CRISPR & {$[143]$} \\
\hline \multirow[t]{2}{*}{ MK8722 } & \multirow[t]{2}{*}{ ADaM } & \multirow[t]{2}{*}{$\beta 1 / \beta 2$} & \multirow[t]{2}{*}{ Skeletal muscle } & \multirow[t]{2}{*}{$\boldsymbol{\lambda}$ Glucose uptake } & Mice/rats & nt & {$[111]$} \\
\hline & & & & & $\begin{array}{l}\text { Non human } \\
\text { primates }\end{array}$ & nt & {$[111]$} \\
\hline \multirow[t]{2}{*}{ PF739 } & \multirow[t]{2}{*}{ ADaM } & \multirow[t]{2}{*}{$\beta 1 / \beta 2$} & \multirow[t]{2}{*}{ Skeletal muscle } & \multirow[t]{2}{*}{$\boldsymbol{\lambda}$ Glucose uptake? } & Mice & $\begin{array}{l}\text { Inducible skeletal } \\
\text { muscle AMPK } \alpha 1 \alpha 2 \mathrm{KO}\end{array}$ & {$[108]$} \\
\hline & & & & & $\begin{array}{l}\text { Non human } \\
\text { primates }\end{array}$ & nt & {$[108]$} \\
\hline
\end{tabular}




\section{Figure legends}

Figure 1: Domains of the mammalian AMPK $\alpha, \beta$ and $\gamma$ subunits.

The crystal structure of AMPK heterotrimeric complex is shown with $\alpha$ subunit (green), $\beta$ subunit (dark blue) and $\gamma$ subunit (mauve) (PDB 1CFF; [82]). The structure shows the activation-relevant phosphosites $\alpha$-Thr172 and $\beta$-Ser108 (brown), two AMP (orange/yellow) molecules bound to CBS-3 and CBS-4 in the $\gamma$ subunit, the allosteric activator A-769662 (red) bound to a pocket formed by the interface between the $\alpha$-kinase domain and the $\beta$-GBD and the kinase inhibitor staurosporine (green) in the active site. Domain structure for AMPK subunit isoforms $(\alpha 1, \alpha 2, \beta 1, \beta 2, \gamma 1, \gamma 2$, and $\gamma 3)$ is presented alongside the structure. AMPK $\alpha$ contains a kinase domain $(\alpha-\mathrm{KD})$ phosphorylated by upstream kinases on the residue Thr172, an autoinhibition domain ( $\alpha$-AID), and a C-terminus domain ( $\alpha$-CTD) that interacts with the $\beta$ subunits. AMPK $\beta$ subunit presents a myristoylation site at the $\mathrm{N}$-terminus, a glycogenbinding domain ( $\beta$-GBD) phosphorylated on the residue Ser108 and a $\alpha$ and $\gamma$ subunit interaction domain ( $\beta$-SID). AMPK $\gamma$ contains $4 \beta$-synthase (CBS) domains binding AMP, ADP, and ATP, but only three of the four potential nucleotide-binding sites contribute to nucleotide regulation, with CBS-2 always unoccupied, CBS-4 permanently bound to AMP (non exchangeable) and CBS-1 and -3 binding AMP, ADP, and ATP interchangeably. NES, nuclear export sequence; RIM, regulatory-subunit-interacting motif; ST-loop, serine/threonine-enriched loop.

Figure 2: AMPK heterotrimer composition in skeletal muscle, liver and macrophage from human and mouse.

A cartoon of the distribution of major AMPK heterotrimeric complexes in human (vastus lateralis) and murine (fast-twitch glycolytic extensor digitorum longus [EDL] and slowtwitch oxidative soleus) skeletal muscle (left panels). The predominant AMPK heterotrimeric complexes are also shown in human and mouse liver and macrophage (right panels). The AMPK heterotrimetric protein composition in human and mouse skeletal muscle was determined and quantified by performing co-immunoprecipitation experiments followed by Western blots using antibodies against all the known AMPK subunit isoforms [62-64]. The 
relative abondance of the subunit isoform in human and mouse liver was estimated by chemical proteomics [67], quantitative ELISA [108] and Western blots analysis [68, 96, 139]. The relative abondance of the AMPK subunit isoforms in human and mouse macrophage was estimated by Western blots analysis [101, 140-142]. Note that the differences in the affinity of the antibodies used to recognize the different AMPK isoforms may result in underestimation or overestimation in the distribution of heterotrimers.

\section{Figure 3: Structures of allosteric direct small molecule AMPK activators and inhibitors.}

Structure of direct small molecule activators binding to the ADaM site located between the $\beta$ GBD and the small lobe of the $\alpha$-kinase domain [selective for complexes containing the $\beta 1$ isoform (turquoise frame) or both $\beta 1$ - and $\beta 2$-isoforms (turquoise/blue frame)], to the $\gamma$ isoform (purple frame) or with unknown interaction site (grey frame). Direct small molecule inhibitor selective for complexes containing the $\beta 2$-isoform (dark frame) is also shown. The crystal structure of AMPK heterotrimeric complex is shown with $\alpha$ subunit (green), $\beta$ subunit (dark blue) and $\gamma$ subunit (mauve) (PDB 1CFF; [82]). The structure shows the activationrelevant phosphosites $\alpha$-Thr172 and $\beta$-Ser108 (brown), two AMP (orange/yellow) molecules bound to CBS-3 and CBS-4 in the $\gamma$ subunit, the allosteric activator A-769662 (red) bound to a pocket formed by the interface between the $\alpha$-kinase domain and the $\beta$-GBD and the kinase inhibitor staurosporine in the active site (green). 


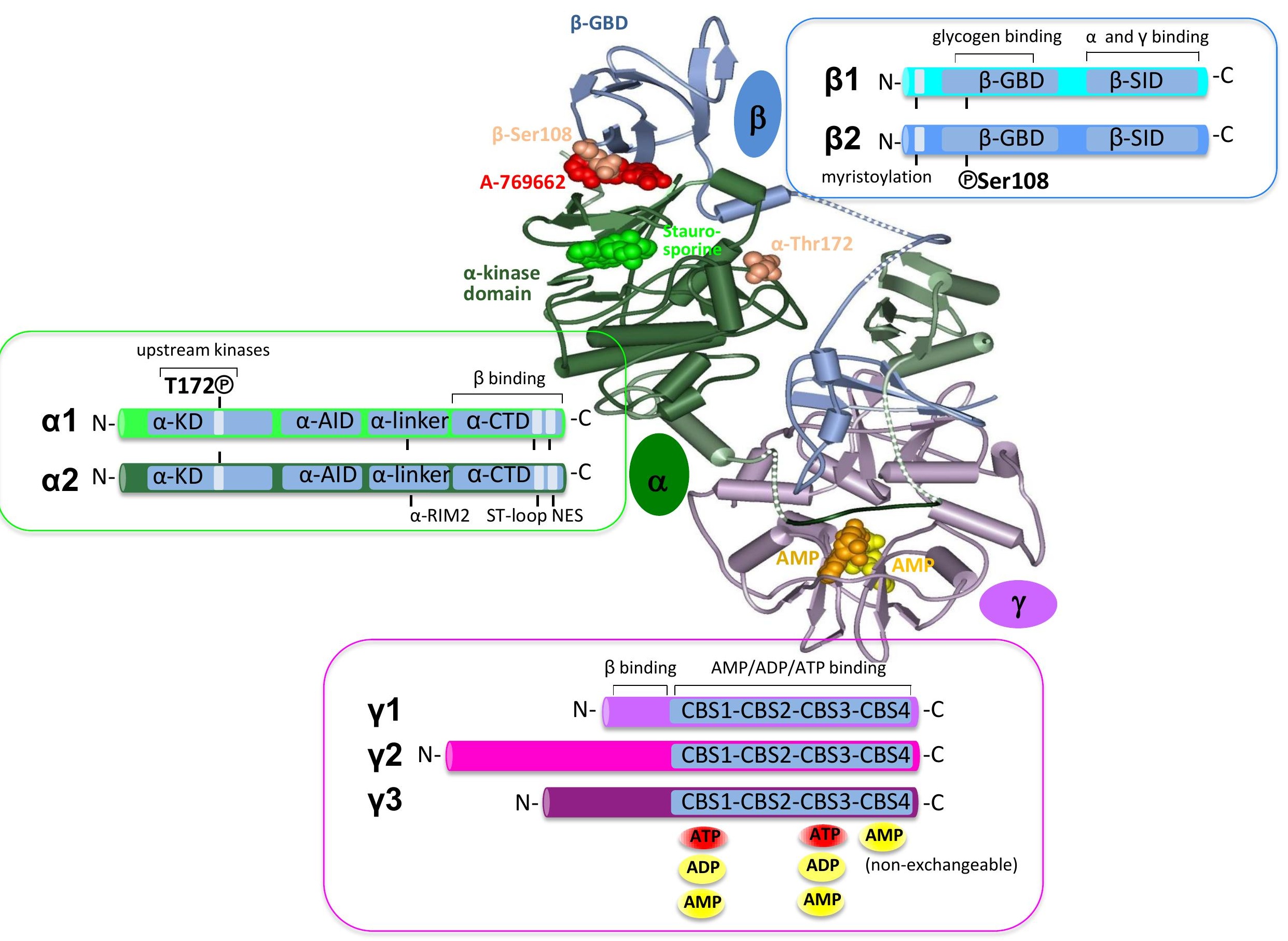




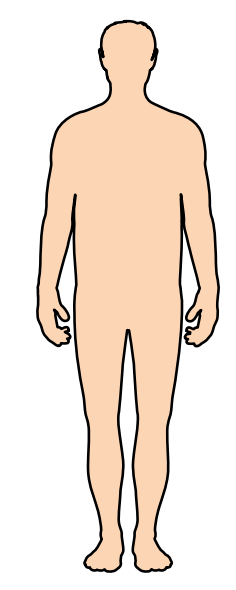

Homo sapiens

Mus musculus
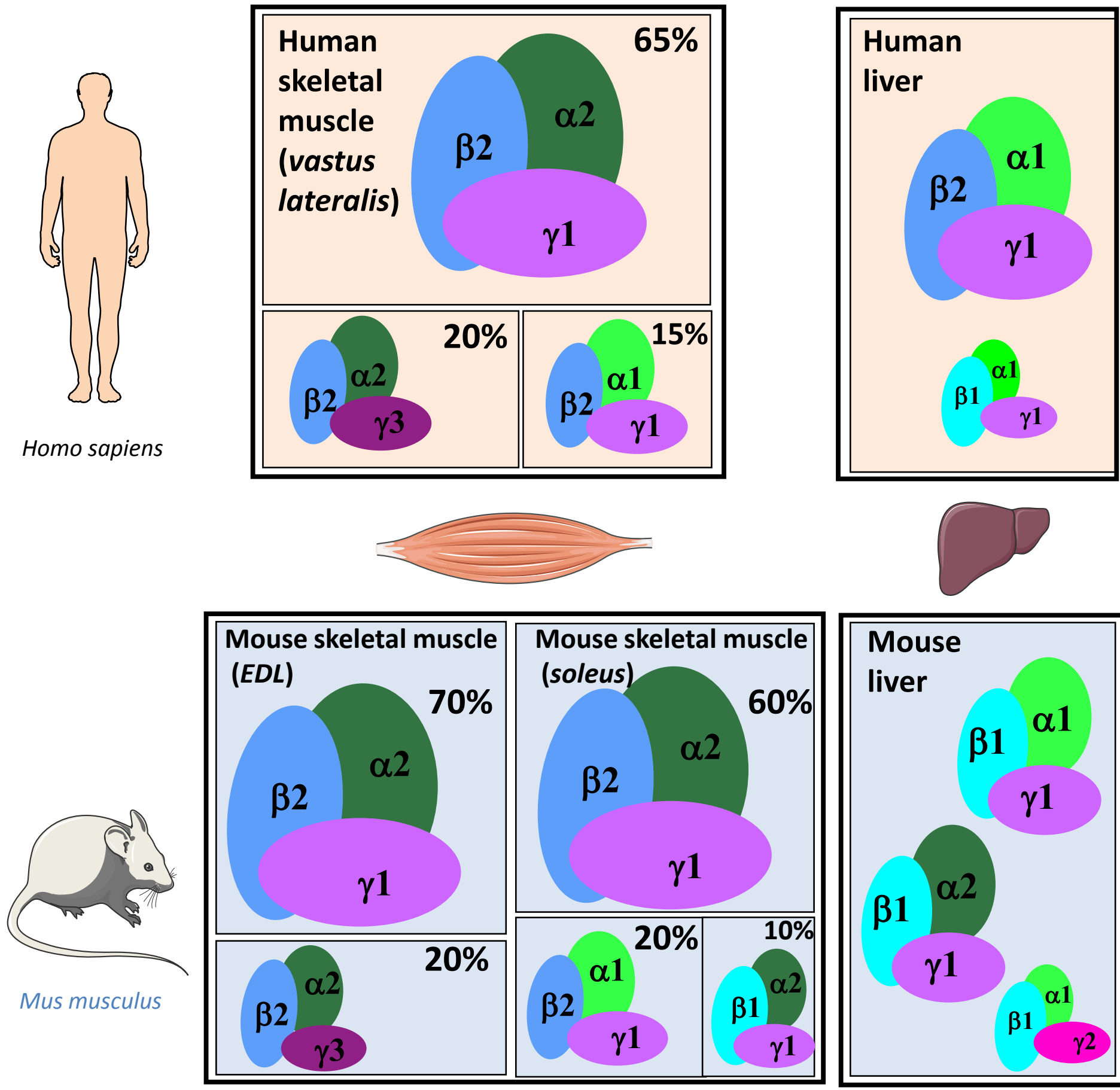

Human

Macrophage

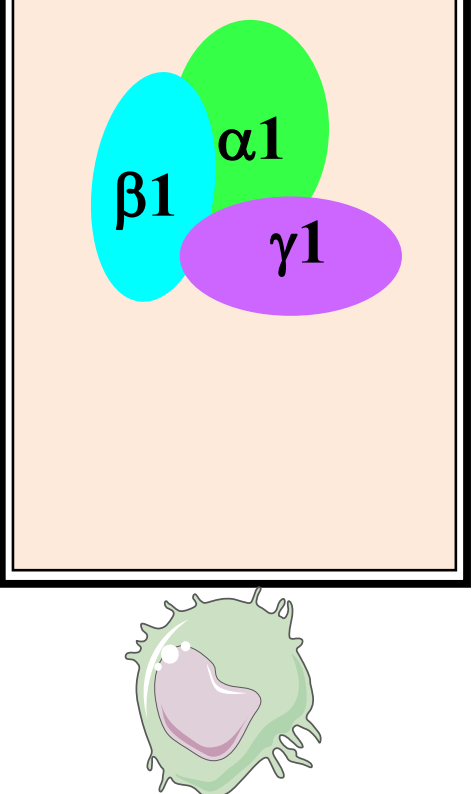

Mouse

macrophage
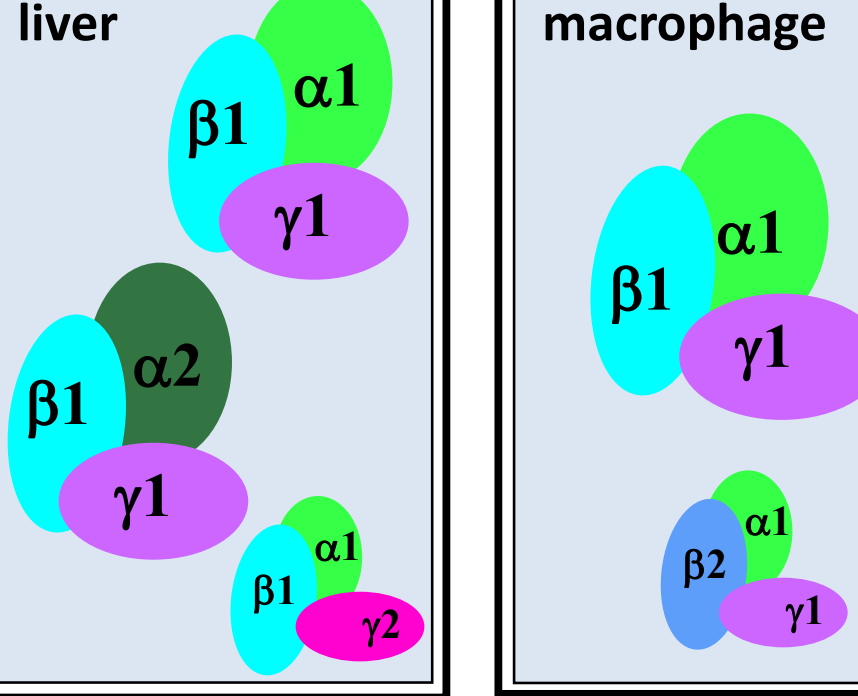
